\title{
Scenario development for estimating potential climate change impacts on crop production in the North China Plain
}

\author{
Chao Chen, ${ }^{\mathrm{a}, \mathrm{b}, \mathrm{c} *}$ Arthur M. Greene, ${ }^{\mathrm{a}}$ Andrew W. Robertson, ${ }^{\mathrm{a}}$ Walter E. Baethgen ${ }^{\mathrm{a}}$ and Derek \\ Eamus $^{\mathrm{b}, \mathrm{c}}$ \\ a International Research Institute for Climate and Society, The Earth Institute at Columbia University, Palisades, NY, USA \\ ${ }^{\mathrm{b}}$ National Centre for Groundwater Research and Training, Flinders University, Adelaide, SA, Australia \\ ${ }^{\mathrm{c}}$ School of the Environment, University of Technology, Sydney, NSW, Australia
}

\begin{abstract}
It is important to investigate potential changes in temperature, precipitation and solar radiation for assessing the impacts of future climate change on agricultural production for specific regions. In this study, climate scenarios of precipitation, temperature and solar radiation for the North China Plain (NCP) were constructed in terms of stochastic daily weather sequences. A nonhomogeneous hidden Markov model (NHMM) was used to downscale daily precipitation projections at 32 stations during winter wheat and summer maize growing seasons for a baseline (1966-2005) and a 21st century (2080-2099) A1B scenario, using selected general circulation models (GCMs). A climatological seasonal cycle of regional-averaged daily reanalysis precipitation was used as input to the down-scaling for the baseline simulation; this input was then scaled by the precipitation changes from GCM projections to generate down-scaled stochastic simulations of precipitation in the 21 st century. Temperature was generated using a weakly stationary generating process, conditional on precipitation occurrence, with 21 st century additive changes taken from the GCMs at the regional scale. Three hypotheses about changes in solar radiation $(-20 \%, 0 \%$ and $20 \%)$ were made considering the large uncertainty in its future change. The down-scaled simulations exhibit station increases in the mean daily rainfall of $13.9-69.7 \%$ in the scenarios driven by the GCM with the projected largest and multi-model mean precipitation increase for the wheat season, with changes of 0.4-29.9\% for the maize season. In the scenario driven by the GCM with the largest projected precipitation decrease, the simulated rainfall decreases at all stations, with changes ranging from -24.6 to $-0.1 \%$ for the wheat and maize seasons, respectively. Temperature increases by about $3.7^{\circ} \mathrm{C}$ for the wheat season and $3.6{ }^{\circ} \mathrm{C}$ for the maize season. Copyright $(\mathrm{C}$ 2013 Royal Meteorological Society
\end{abstract}

KEY WORDS precipitation; temperature; solar radiation; climate change scenario; GCMs; hidden Markov model

Received 12 April 2012; Revised 10 December 2012; Accepted 16 December 2012

\section{Introduction}

Climate change is expected to have major impacts on agriculture and water resources (Evans, 1996), although regional details are often uncertain. The changes in different climate variables, such as temperature, precipitation and solar radiation, have different impacts on agricultural production (Spaeth et al., 1987; Lobell and Asner, 2003; Ludwig and Asseng, 2006). Increases in temperature will affect the duration of phenological phases, growth rate, transpiration rates, etc. Changes in solar radiation will affect photosynthesis and evapotranspiration, while precipitation change will affect soil moisture supply and grain yield. To assess the impacts of climate change on agricultural system, it is important to quantify expected changes in temperature, precipitation and solar radiation for specific regions, and to estimate the role of different sources of uncertainty.

\footnotetext{
* Correspondence to: C. Chen, International Research Institute for Climate and Society, The Earth Institute at Columbia University, Palisades, NY, USA. E-mail: ccchenchao2009@163.com
}

The most widely used tools to construct climate scenarios for impact assessment are general circulation models (GCMs) (Giorgi and Mearns, 1991; Viner and Hulme, 1994). However, their relatively low resolution limits the direct use of their outputs in scenario development. Precipitation, in particular, is poorly represented both spatially and temporally in GCMs simulations. Large uncertainty exists regarding the projection of precipitation (Dai, 2006), although projected changes in temperature are more reliable (Hulme et al., 1992). The projected changes in solar radiation tend to mirror those of precipitation, with large discrepancies among different GCMs. Therefore, projected changes in these variables should be tailored to their area of application in order to develop more realistic climate change scenarios relevant to agricultural applications.

The North China Plain (NCP) is one of the largest agricultural production regions in China, covering a total area of $320000 \mathrm{~km}^{2}$ (Figure 1). During the last three to four decades, land use in the NCP has consisted of a double cropping system of winter wheat (October-May) followed by maize in the summer (June-September), 
providing about $50 \%$ of the wheat and $30 \%$ of the maize for the nation. However, agriculture in this area is under water stress (Wang et al., 2001), and the region is thus potentially vulnerable to future climate change. Therefore, understanding how agricultural production will respond to potential changes in climate is an important step for developing sustainable agriculture and corresponding adaptation strategies (Mizina et al., 1999; Reilly and Schimmelpfennig, 1999).

In this study, we attempt to construct climate scenarios for precipitation, temperature and solar radiation during the winter wheat and summer maize seasons in the NCP, in terms of stochastic daily weather sequences. Under rainfed conditions, precipitation is the most important climate factor affecting crop yield in the NCP (Chen et al., 2012). Compared with temperature and solar radiation, there are much larger spatial variations in precipitation in the study region (Wu et al., 2006 2008). It is essential to diagnose its variations over space, as well as time. A number of statistical and dynamical down-scaling methods have been developed to derive regional climate change scenarios from the output of GCMs (Hewitson and Grane, 1996; Murphy, 2000; Fan et al., 2005). Compared with dynamic down-scaling, statistical down-scaling is computationally inexpensive and implementation is relatively straightforward. The nonhomogeneous hidden Markov model (NHMM), a stochastic down-scaling model, can downscale rainfall fields in both spatial and temporal dimensions by linking stationscale daily rainfall to large-scale atmospheric predictors. The model has been widely utilized in many downscaling studies and proved to be a promising approach to downscale precipitation at multiple locations (Hughes and Guttorp, 1994; Bates et al., 1998; Hughes et al., 1999; Robertson et al., 2004; Liu et al., 2011). Given the effectiveness of the NHMM at simulating the statistics of precipitation at both spatial and temporal scales, it is used in this study to downscale daily rainfall at 32 stations during the wheat and maize seasons for the 20th century, with interpolated regional-averaged reanalysis precipitation as input, and for 21 st century, the input for 20th century scaled by the precipitation changes from GCM outputs. Temperature, as well as solar radiation, is simulated using the generating process, conditional on precipitation occurrence (Matalas, 1967), considering that the NHMM is currently restricted to simulating precipitation and temperature and solar radiation have relatively low spatial variation. A recent study suggests that changes in solar radiation in the 20th century may have had important effects on crop yields in the NCP (Chen et al., 2012). There are large uncertainties regarding future change in solar radiation and consequently in this study we considered three possible scenarios. One maintains the current aerosol concentration is unchanged in the atmosphere, which results in future solar radiation remaining near its current level. A second scenario has a reduced aerosol concentration in the atmosphere due to improved environmental conditions. This leads to an increase in solar radiation (Wild et al., 2005). The final scenario considered has an increased aerosol concentration due to a rapid industrial development, leading to a decrease in solar radiation.

The remainder of this paper is organized as follows. The observational and GCM data used as model input are presented in Section 2. Section 3 describes the NHMM used to down-scale daily precipitation, the generating process used to simulate temperatures and the hypotheses used to generate solar radiation. Section 4 covers the details of model applications. The main simulation results of precipitation and temperature for the two crop seasons are presented in Section 5. The summary and conclusions are provided in Section 6.

\section{Data}

\subsection{Observed climate data}

Forty years (1966-2005) of daily precipitation, maximum and minimum temperature and sunshine hours at 32 stations uniformly distributed over the NCP were used in this study (Figure 1). These data were obtained from the China Meteorological Administration (CMA). Solar radiation was not available for most of the stations. Therefore sunshine hours, which were available, were converted into solar radiation using the Angstrom equation (Wang et al., 2008). Estimated solar radiation with this equation matched well with the observed values at the Beijing and Yucheng sites (data not shown), located in the northern and central parts of the NCP, respectively.

Figure 2 shows the climatological rainfall and its decomposition in terms of rainfall occurrence probability (defined as days receiving $\geq 1 \mathrm{~mm}$ ) and mean daily intensity during the wheat and maize seasons. For the wheat season the mean daily rainfall, occurrence probability and mean intensity are all low, with about $1 \mathrm{~mm}$ of mean daily rainfall and less than $20 \%$ occurrence probability at most stations (Figure 2(a)-(c)), while for the maize season, they are much larger (Figure 2(d)-(f)). This is because $60-70 \%$ of the rainfall occurs during summer in the study region. The mean seasonal variations in daily rainfall, temperature and solar radiation during the two crop seasons at ten selected stations, which are located from north to south and can roughly represent the climate conditions in the NCP, are shown in Figure 3, in terms of 40-years average for each pentad. Rainfall during the wheat season exhibits a minimum towards the end of December and a maximum in May (Figure 3(a)). During the maize season, it increases to a maximum from June to July, and then decreases from August onward (Figure 3(b)). The climate in the NCP has the characteristic of simultaneous seasonal pattern of temperature and moisture. Mean daily temperature during the wheat season decreases to a minimum in the beginning of January, and increases towards the end of May (Figure 3(c)). It increases from June to July, and then decreases to a minimum in the end of September (Figure 3(d)). Mean daily solar radiation during the wheat season decreases to a minimum towards the end of December, and then 


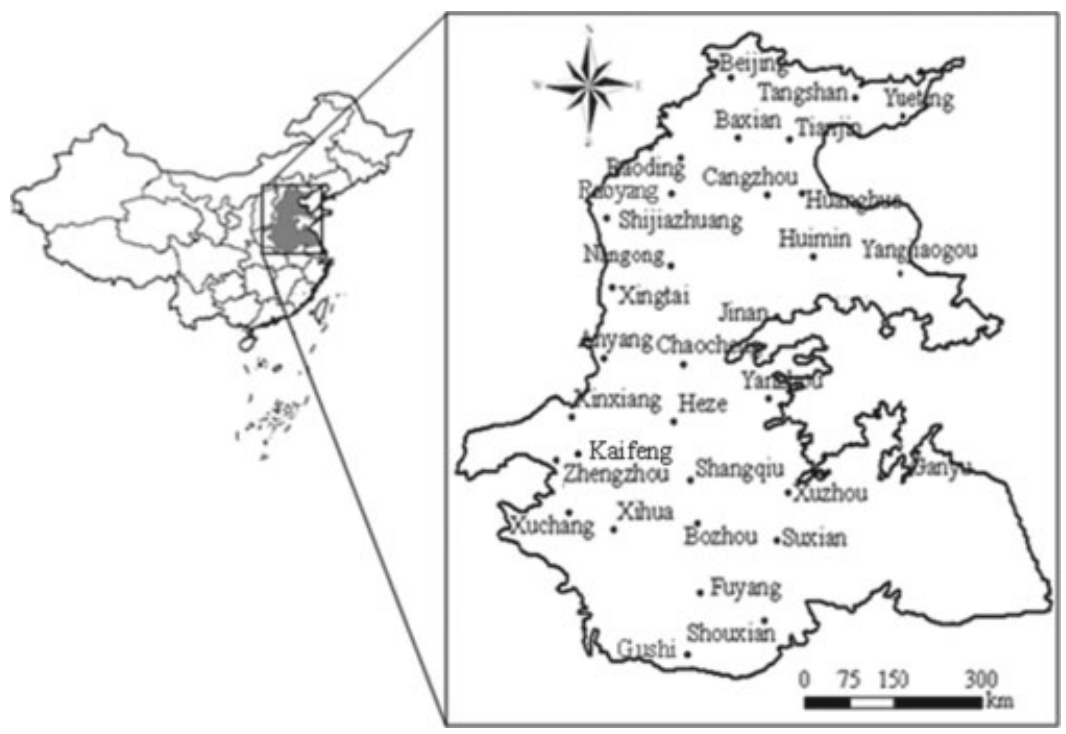

Figure 1. The North China Plain and the location of meteorological stations used in this study.

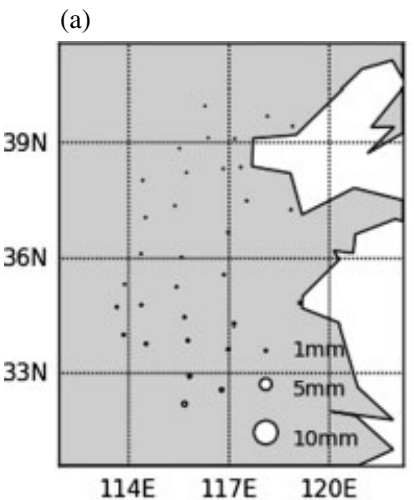

(d)

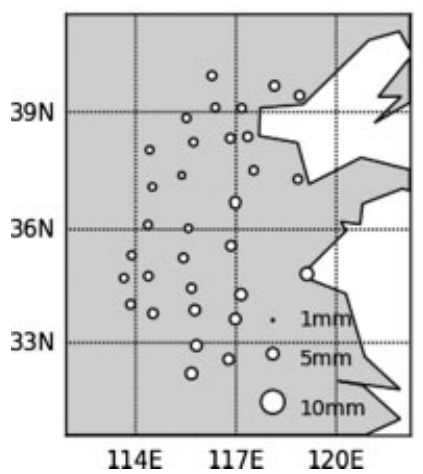

(b)

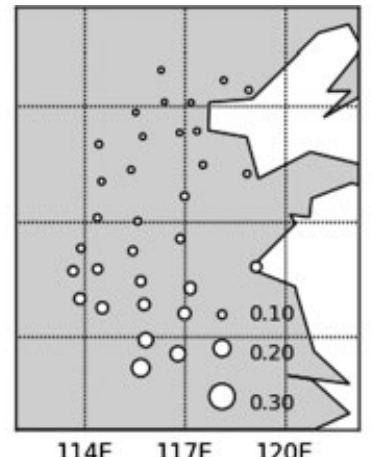

(e)

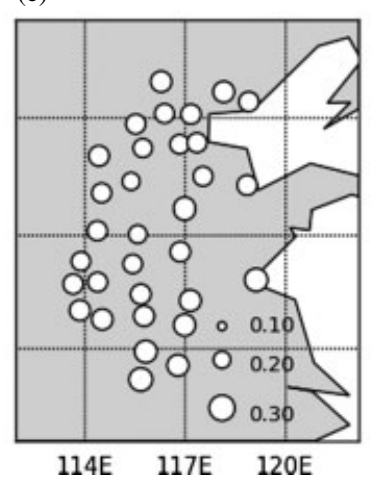

(c)

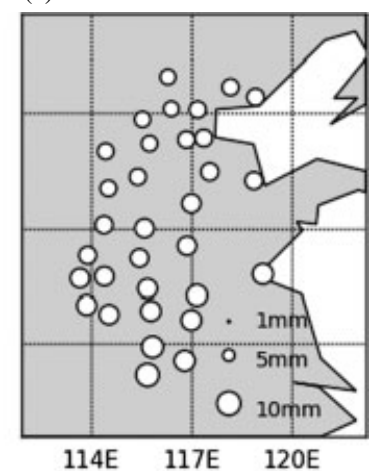

(f)

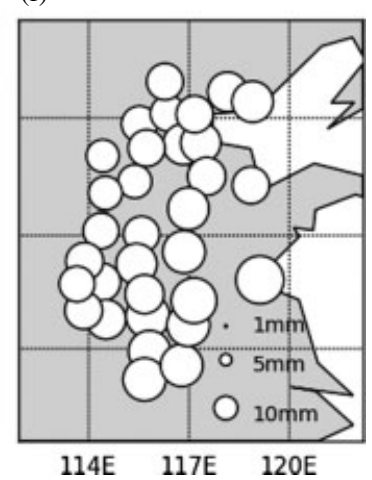

Figure 2. The climatological mean daily rainfall $(\mathrm{mm})(\mathrm{a}, \mathrm{d})$, probability of rainfall occurrence (b, e) and mean daily intensity (mm), i.e. mean rainfall amount on wet days with $\geq 1 \mathrm{~mm}(\mathrm{c}, \mathrm{f})$, during the wheat season (upper panel) and maize season (lower panel).

increases to a maximum in the end of May (Figure 3(e)). During the maize season, it exhibits a maximum in early June, and then decreases onward (Figure 3(f)), partly associated with the summer precipitation maximum. It can be seen from Figure 3(c)-(f) that the climatological temperature during two crop seasons increases from north to south, while the climatological solar radiation during both wheat and maize seasons decreases gradually from north to south.

\subsection{Reanalysis precipitation data}

The climatological annual cycle of reanalysis precipitation over a regional window $\left(32-40^{\circ} \mathrm{N}, 114-121^{\circ} \mathrm{E}\right)$ derived from the 40-years (1966-2005) NCEP-NCAR reanalysis dataset (Kalnay et al., 1996), was used to define the input to the down-scaling for the baseline simulation. The reanalysis precipitation field is produced by assimilating available observed atmospheric data (using a high level of quality control), with a global numerical 
(a)

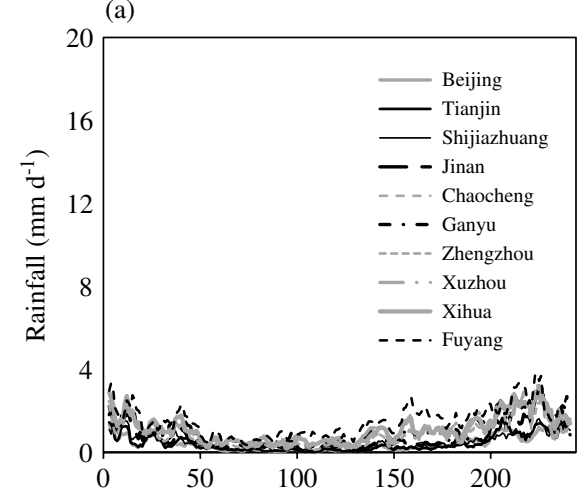

(c)

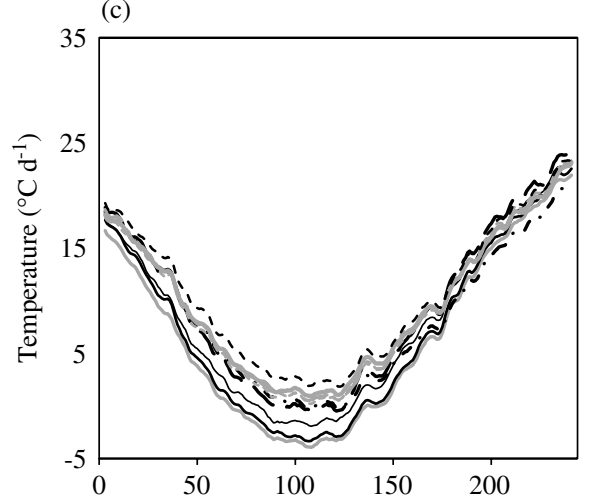

(e)

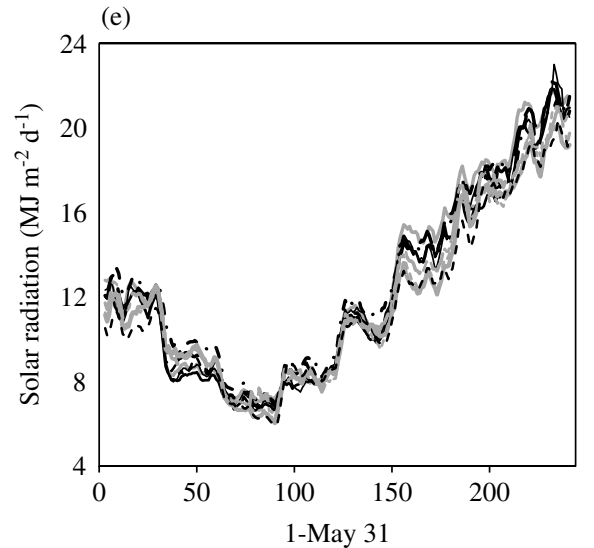

(b)
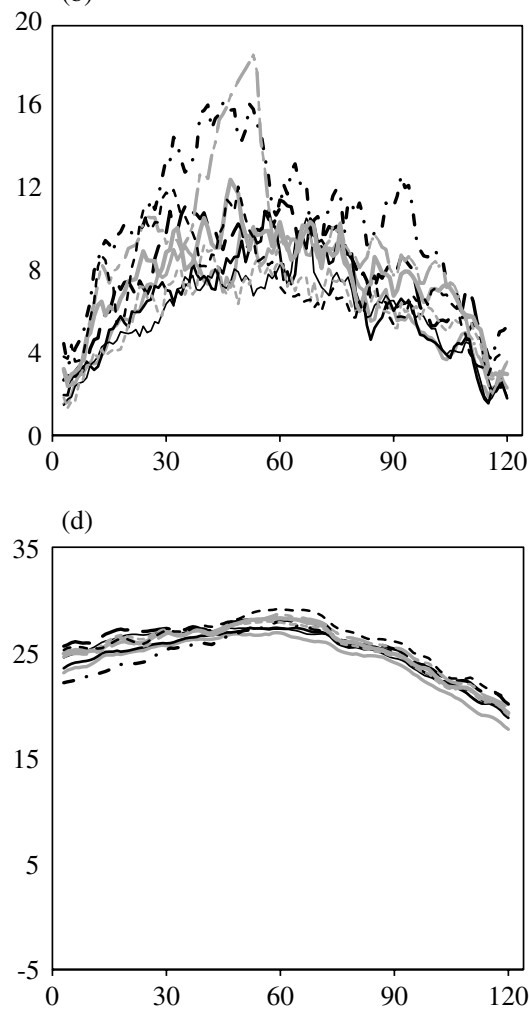

(f)



Figure 3. The mean seasonal cycle of mean daily rainfall (a, b), temperature (c, d) and solar radiation (e, f) during the wheat season (left panel) and maize season (right panel) at 10 selected stations, computed using pentad block means.

weather prediction model. The reanalysis precipitation used here can provide an appropriate large-scale input to the down-scaling model for precipitation simulations. In fact it may be considered to be the 'perfect predictor' because the NHMM, in simulating precipitation, is driven by the actual precipitation variable.

\subsection{GCM data}

Regionally averaged monthly precipitation changes from GCM projections were used to scale the reanalysis precipitation input to construct down-scaled stochastic simulations of daily precipitation in the 21 st century. Use of the GCM's intrinsic precipitation fields is consistent with the 'perfect predictor' framework mentioned above. Fifteen GCMs (Figure 4, Table I) wereselected for which both precipitation and temperature (daily maximum and minimum) are available for both the 20th century (1966-2005) and the 21st century (2080-2099) A1B scenario. The GCMs are from the Coupled Model Intercomparison Project version 3 dataset (CMIP3) (Meehl et al., 2007), which underpin much of the research discussed in the Fourth Assessment Report of the Intergovernmental Panel on Climate Change (IPCC) (Solomon et al., 2007). Projected precipitation changes vary in both direction and magnitude among models (Figure 4, Table I), indicating the limitation of using a single precipitation scenario. Thus, three different precipitation scenarios for the 21 st century were constructed, for each of the two crop seasons. They were driven by: (1) the GCM with the largest projected precipitation increase, 


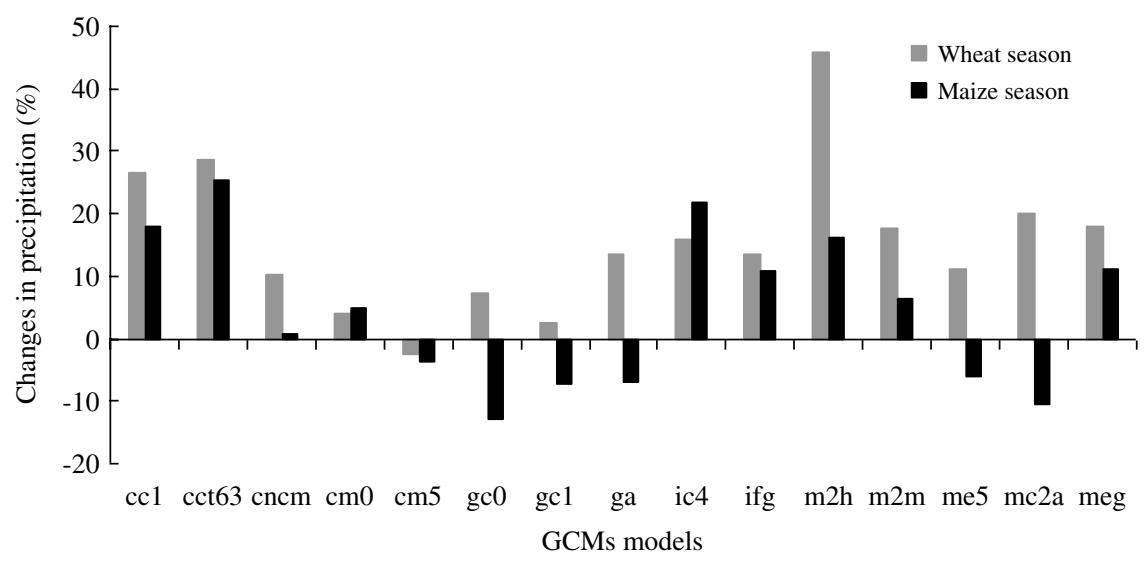

Figure 4. The changes in precipitation during the wheat and maize seasons projected by 15 selected GCMs. The model names are shown in Table I.

Table I. GCMs in the CMIP3 archive (Meehl et al., 2007) used in this study.

\begin{tabular}{lc}
\hline Group & Model \\
\hline CCCMA (Canada) & CGCM-3.1 (cc1) \\
CCCMA & CGCM-3.1(T63) (cct63) \\
CNRM (France) & CM3 $(\mathrm{cncm})$ \\
CSIRO (Australia) & CSIRO-Mk3.0 (cm0) \\
CSIRO & CSIRO-Mk3.5 (cm5) \\
GFDL (USA) & GFDL-CM2.0 (gc0) \\
GFDL & GFDL-CM2.1 (gc1) \\
GISS (USA) & GISS-AOM (ga) \\
IPSL (France) & IPSL-CM4 (ic4) \\
IAP (China) & FGOALS-g1.0 (ifg) \\
CCSR/NIES/JAMSTEC (Japan) & MIROC3.2 (hires) (m2h) \\
CCSR/NIES/JAMSTEC & MIROC3.2 (medres) (m2m) \\
MPI (Germany) & ECHAM5/MPI-OM (me5) \\
MRI (Japan) & MRI-CGCM2.3.2 (mc2a) \\
MIUB (Germany/Korea) & MIUB-CHOG-g (meg) \\
\hline
\end{tabular}

which was MIROC3.2(hires) for the wheat season and CGCM-3.1 (T63) for the maize season (Figure 4, Table I) (hereinafter referred to as precipitation scenario W); (2) the GCM multi-model mean (precipitation scenario $\mathrm{M}$ ) and (3) the GCM with the largest projected precipitation decrease, which was CSIRO-Mk3.5 for the wheat season and GFDL-CM2.0 for the maize season (precipitation scenario D).

The projected changes in maximum and minimum temperature during both wheat and maize seasons over the NCP show no large differences among the 15 selected GCMs (Figure 5). Therefore, one single temperature scenario for the 21st century was developed for each of the two crop seasons, in which the changes in regionalaveraged maximum and minimum temperature projected by the multi-model mean under A1B scenario were applied to the observed data to construct the temperature scenario.

\subsection{Hypotheses about the change in solar radiation}

Considering the large uncertainty in solar radiation change due to the uncertainty of human emissions in the future, three hypotheses about its change in the $21 \mathrm{st}$ century were developed, the first $\left(S_{0}\right)$ that it will not change in the 21 st century, the second $\left(S_{-20}\right)$ that it will decrease by $20 \%$ and the last $\left(S_{20}\right)$ that it will increase by $20 \%$.

\section{Models}

\subsection{Precipitation}

The NHMM model was used to generate spatially disaggregated rainfall simulations at 32 stations during wheat and maize seasons in the NCP. The model decomposes the daily precipitation field on a network of stations into a few discrete hidden states $S_{1: t}=\left(S_{1}, \ldots, S_{t}\right)$, which are modelled as first-order Markov dependent in time. $S_{t}$ takes values from 1 to $K$, where $K$ is the selected number of states. Each hidden state is associated with a distinct atmospheric circulation regime. The model also assumes that observed rainfall at each station on a certain day $t$ only depends on the state variable on that day, which captures spatial dependence between stations implicitly. The transition probabilities are defined to be a function of a 'predictor' input time series $X_{1: t}$, corresponding to an exogenous variable that can influence the evolution of the weather-state sequence $S_{1: t}$ :

$$
P\left(S_{t} \mid S_{1: t-1}, X_{1: t}\right)=P\left(S_{t} \mid S_{t-1}, X_{t}\right)
$$

where $t$ is time in terms of days, $P$ represents the transition probability between states in going from time (i.e. day) $t-1$ to time $t, X$ is the predictor vector and $S$ is the hidden state.

The hidden state $S_{t}$ on day $t$ depends both on the predictor vector $X_{t}$ for day $t$ and the value of the hidden state $S_{t-1}$ on day $t-1$, but not on any earlier days, consistent with a first-order Markov process. The transition probabilities between states can vary in time, which allows external inputs to influence the rainfall characteristics between one year and another.

For each station and state, daily rainfall amount is modelled as a finite mixture of components, consisting 

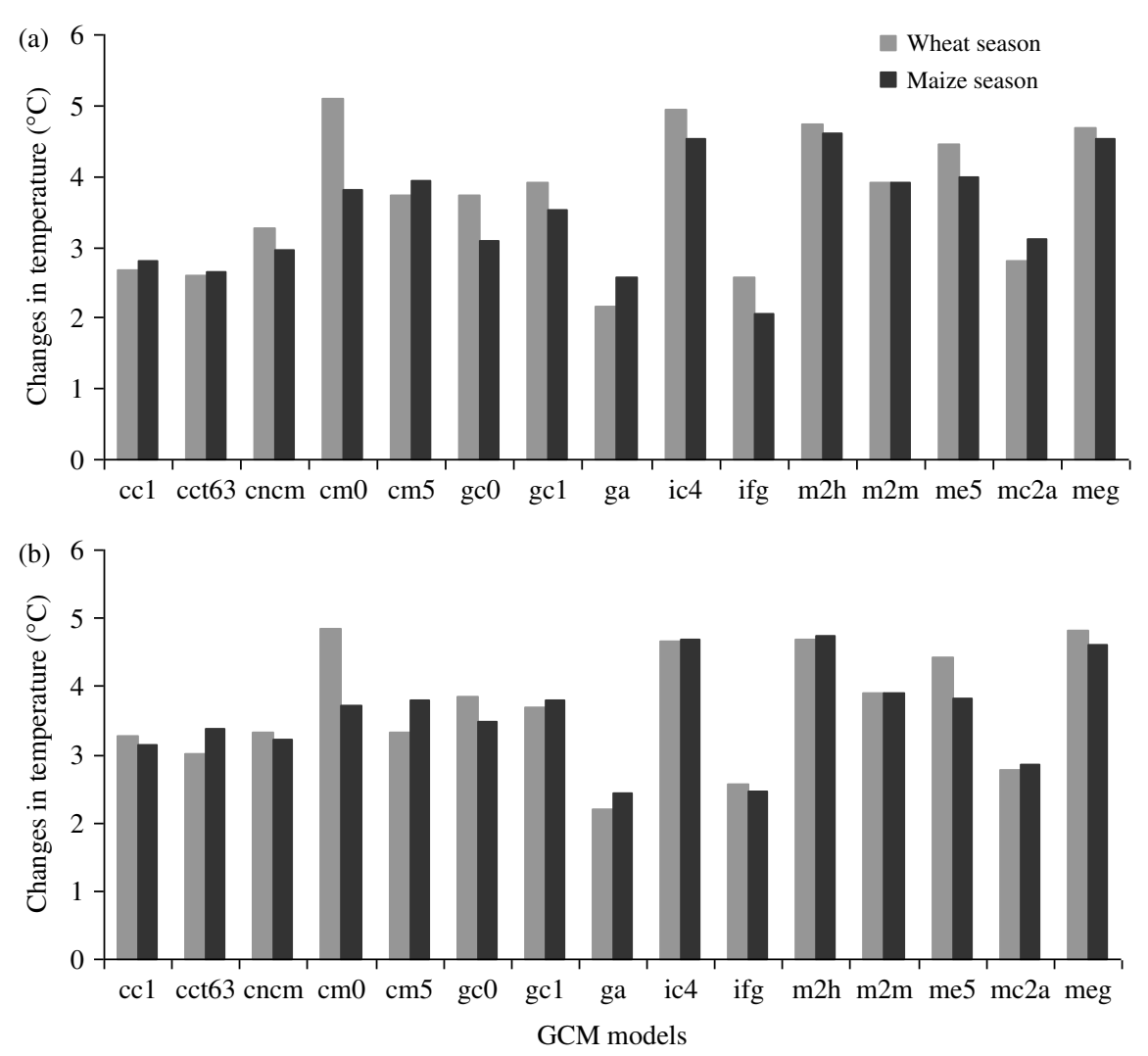

Figure 5. The changes in maximum (a) and minimum (b) temperatures during the wheat and maize seasons derived from 15 selected GCMs. The model names are shown in Table I.

of a delta function to model dry days, and a combination of two exponentials to model rainfall amounts on wet days. A mixture of two exponentials is able to represent well the daily rainfall amounts (Wilks and Wilby, 1999). In this paper, the transition probabilities are defined as a logistic function of regionally-averaged precipitation derived from the NCEP-NCAR reanalysis data set. The predictor values are related to the state-to-state transition probabilities according to a polytomous logistic regression (Robertson et al., 2004):

$$
P\left(S_{t}=i \mid S_{t-1}=j, X_{t}=x\right)=\frac{\exp \left(\sigma_{j i}+\rho_{i}^{\prime} x\right)}{\sum_{k=1}^{K} \exp \left(\sigma_{j k}+\rho_{k}^{\prime} x\right)}
$$

where $i$ and $j$ are the modelled states on day $t$ and $t-1$, respectively, $x$ is the value of predictor $X, \sigma_{j i}$ and $P^{\prime}{ }_{i}$ are parameters being fit, $k$ represents the number of hidden states, $P, X$ and $S$ are the same as in the Equation (1).

For a fixed number of hidden states $K$, the NHMM parameters $\Theta$ can be learnt by searching for those that best fit the observed data. To do this, the maximum likelihood principle is employed here. The parameters $\Theta$ that maximize the conditional probability of the observed values are determined from the historical station rainfall dataset over the training period, here 1966-2005. The conditional probability is a function of $\Theta$, referred to as the likelihood:

$$
\begin{aligned}
L(\Theta) & =P\left(R_{1: T} \mid X_{1: T}, \Theta\right) \\
& =\sum_{S_{1: T}} P\left(S_{1} \mid X_{1}\right) \prod_{t=2}^{T} P\left(S_{t} \mid S_{t-1}, X_{t}\right) \prod_{t=1}^{T} P\left(R_{t} \mid S_{t}\right)
\end{aligned}
$$

where $L(\Theta)$ is the conditional log-likelihood of the observed precipitation data, $R_{1: T}$ represents a precipitation occurrence vector for day 1 to $t, P, X$ and $S$ are the same as the Equation (2).The maximum likelihood parameter values are estimated using the expectationmaximization (EM) algorithm (Dempster et al., 1977) integrated into the NHMM code. Details of the EM estimation algorithm were descried in Robertson et al. (2003).

\subsection{Maximum and minimum temperature and solar radiation}

The generating process described by Matalas (1967) was used to simulate daily maximum and minimum temperatures and solar radiation at 32 stations during the wheat and maize seasons, under the baseline and in the 21 st century. This is a weakly stationary stochastic process that maintains dependencies between weather variables on the same day and from day to day. Here, it generates maximum and minimum temperatures and solar radiation based on the determined time dependence 
and interdependence structures by analyzing the historical weather data (AbouRizk and Wales, 1997).

The analysis procedure involves reducing the historical weather data series into residual elements, with respect to the mean seasonal cycle of temperature and solar radiation. The daily means and standard deviations of each variable were calculated for wet days and dry days, respectively. Fourier series was then used to smooth the daily means and standard deviations to obtain periodic means and standard deviation for each calendar day (Richardson, 1981). The residual elements were determined by removing the smoothed periodic mean and standard deviation:

$$
\begin{array}{ll}
X_{p, i}(j)=\frac{X_{p, i}(j)-\bar{X}_{i}^{0}(j)}{\sigma_{i}^{0}(j)} & Y_{p, i}=0 \\
X_{p, i}(j)=\frac{X_{p, i}(j)-\bar{X}_{i}^{1}(j)}{\sigma_{i}^{1}(j)} & Y_{p, i}>0
\end{array}
$$

where $\bar{X}_{i}^{0}(j)$ and $\sigma_{i}^{0}(j)$ are the mean and standard deviation for a dry day $\left(Y_{p, i}=0\right), \bar{X}_{i}^{0}$ and $\sigma_{i}^{1}(j)$ are the mean and standard deviation for a wet day $\left(Y_{p, i}>0\right)$, and $X_{p, i}(j)$ is the residual component for variable $j$.

These residual series obtained from the maximum temperature, minimum temperature and solar radiation were generally dependent in time and correlated. To calculate these interdependences, cross correlation coefficients between residual series elements on the same day, and serial correlation coefficients between series elements from day to day were calculated to generate new residuals:

$$
X_{p, i}(j)=A X_{p, i-1}(j)+B \varepsilon_{p, i}(j)
$$

where $X_{p, i}(j)$ and $X_{p, i-1}(j)$ are $(3 \times 1)$ matrices for days $i$ and $i-1$ of year $p, \varepsilon_{p, i}(j)$ is a $(3 \times 1)$ matrix of independent random components, and $A$ and $B$ are $(3 \times 3)$ matrices, $j=1,2,3$ are residuals of maximum temperature, minimum temperature and solar radiation, respectively.

Stochastic generation of new sequences of the residual of weather variables proceeds using the weakly stationary generating process by defining covariance matrices. More details about the mathematical procedures of the model for generating maximum and minimum temperature are given in Yevjevich (1972) and Richardson (1981).

\section{Methodology}

\subsection{Generation of precipitation scenarios}

\subsubsection{Model training}

The climatological monthly mean reanalysis precipitation described above was linearly interpolated to daily resolution to drive the NHMM. The daily interpolation was carried out with the monthly mean values specified at the mid-points of each month, from October through May for the wheat season and from June through September for the maize season. The linearly interpolated daily precipitation was used only as an exogenous variable, to drive the NHMM. It should be noted that it is only the shape (including amplitude) of the seasonal cycle of interpolated daily precipitation that plays a role in the simulation of precipitation in the NHMM. The daily precipitation sequences generated by the NHMM have realistic wetand dry-day statistics. The model was trained using the observed daily rainfall and the interpolated daily reanalysis precipitation. During the training process, states of daily rainfall occurrence and rainfall parameters, characterized as the probability of rain and mean daily intensity (i.e. amount on wet days) were inferred by the NHMM.

\subsubsection{Description of states}

Based on the work of Robertson et al . (2004), cross validation was used to select the optimal number of hidden states $K$ in the NHMM. In this process the seven nonoverlapping 5-years blocks of data were withheld in turn and the model with different values of $K$ was trained on the remaining 35 years of data. Then the simulated rainfall fields were compared with the observed rainfall properties for the withheld 5-years validation periods. In each simulation, the EM algorithm was run 10 times with different initial random seeds and the run with the maximum log-likelihood value selected. We examined the log-likelihood for each model with $K=2-7$ and found its value to increase monotonically with $K$. Values started to flatten out from $K=4$. The normalized Bayes information criterion (BIC), a penalized likelihood measure, was also examined to determine the appropriate number of states. It reached its minimum value at $K=4$. Thus, both likelihood and BIC scores indicated that $K=4$ was a reasonable choice for the number of the states.

The four states from the trained model are summarized in Figure 6 for the wheat season and in Figure 7 for maize season, in terms of the probability of rainfall (Figures 6(a)-(d) and 7(a)-(d)) and the mean daily intensity (Figures 6(e)-(h) and 7(e)-(h)). The latter was calculated using the fitted parameters of the mixed twocomponent exponential distribution (Robertson et al., 2004). State 3 exhibited both low occurrence probabilities and intensities (dry) (Figures 6(c) and 7(c)). State 2 was characterized by the highest probabilities of rainfall and relatively high intensities over the region (wettest) (Figures 6(b) and 7(b)). State 1 had the largest occurrence and wet-day amount in the south (wet in the south) (Figures 6(a) and 7(a)), while state 4 had the largest occurrence and wet-day amount in the north (wet in the north) (Figures 6(d) and 7(d)).

Figure 8 shows the daily climatology of the state sequence derived using the Viterbi algorithm (Viterbi, 1967), from which the relative state occupation frequencies can be easily seen. The Viterbi algorithm is a dynamic programming algorithm for assigning each day to its most probable state sequence, given a fitted NHMM. In the simulation of the NHMM, all the states contributed to the precipitation values that are simulated. However, 
(a)

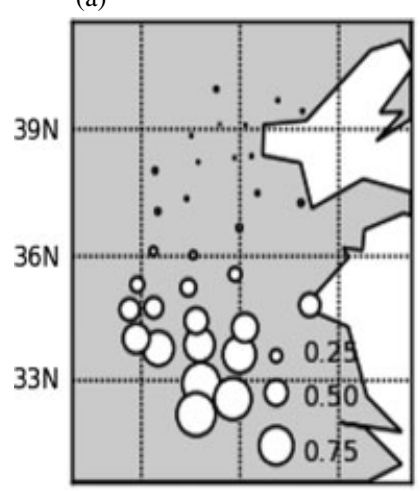

(e)

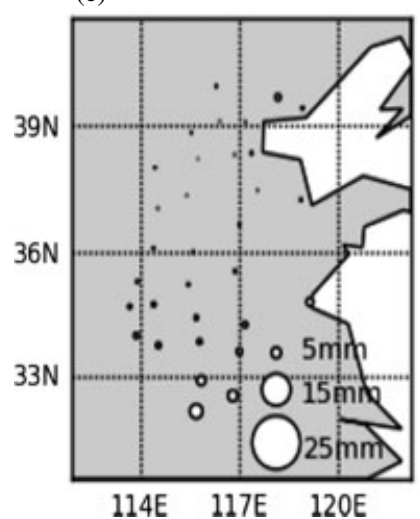

(b)

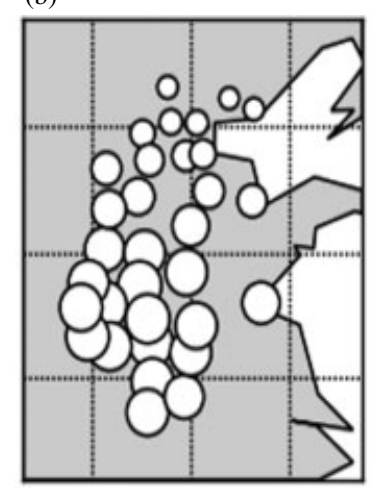

(f)

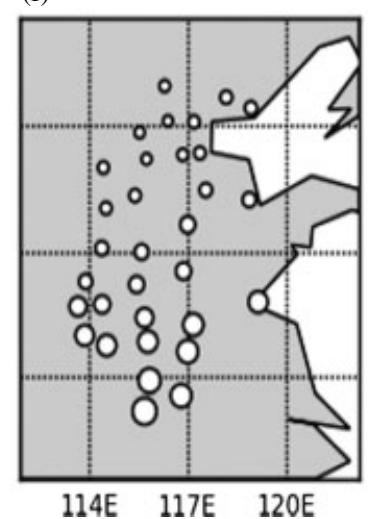

(c)

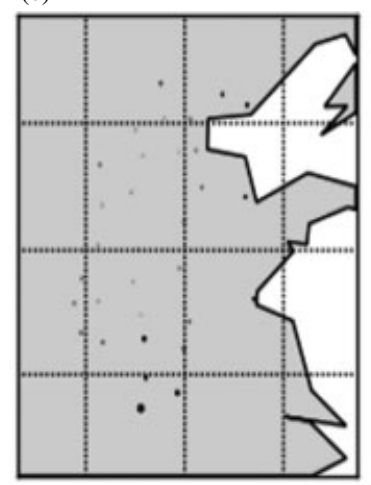

(g)

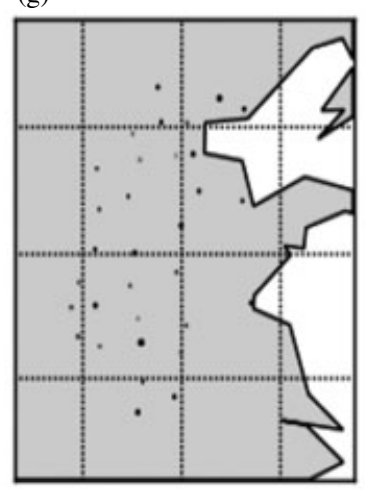

114E 117E 120E (d)

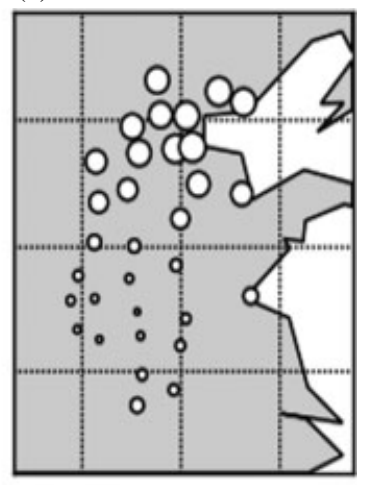

(h)

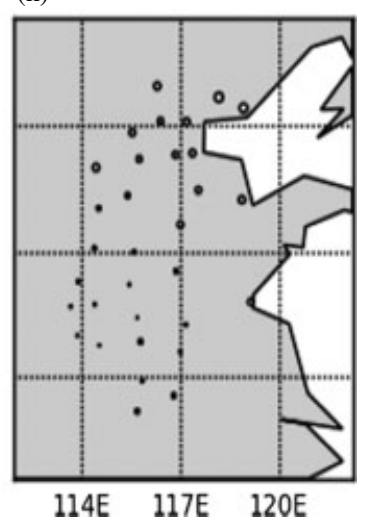

Figure 6. Probability of rain $(\mathrm{a}-\mathrm{d})$ and mean daily intensity $(\mathrm{e}-\mathrm{h})$ during the wheat season for states $1-4$, shown in the corresponding columns.

some states occur more frequently than others. For the wheat growing season, Figure 8(a) indicates that the dry state (State 3) occurs more often with about dry days of 195 , indicating the sparse precipitation. There is no significant difference in the probability space occupied among the other three states (wettest, wet in the south and wet in the north). For the maize season, dry state is dominant in the early and late parts of the season, with the four states occupying almost equal fractions of probability space in the middle of the season (Figure 8(b)).

\subsubsection{Simulation of precipitation}

Using the estimated parameters of the NHMM and the interpolated daily reanalysis precipitation, an ensemble of ten 40-years simulations of daily rainfall was generated to construct baseline precipitation scenarios for the wheat and maize seasons, respectively.

Input variables for the two crop seasons in the 21 st century were constructed by combining the interpolated daily reanalysis precipitation with GCM-based regional precipitation change. The proportional changes in monthly mean precipitation (October-May for wheat, June-September for maize) derived from each of the three selected GCMs simulations under A1B scenario mentioned in Section 2 were calculated. The projected precipitation changes were used to scale the interpolated daily reanalysis precipitation:

$$
y_{i}=x_{i} \times\left(1+\Delta_{j}\right)
$$

where $y_{i}$ is the scaled daily precipitation on day $i ; x_{i}$ is the daily-interpolated reanalysis precipitation on day $i$ during wheat or maize season; $\Delta_{j}$ is the fractional change in monthly precipitation over the study region projected by GCM, for wheat season, $j=1,2, \ldots, 8$, representing October, November, ..., May, respectively, and $j=1,2$, 3, 4 for maize season, representing June, July, August, September, respectively. Therefore, the seasonal cycle changes of precipitation projected by the GCMs are critical to the NHMM simulations of rainfall for the 21 st century. By using the scaled daily precipitation as input to the NHMM down-scaling, precipitation for the 21 st century was finally simulated. Ten stochastic daily simulations of rainfall were generated for both wheat and maize seasons for each precipitation scenario.

\subsection{Generation of temperature and solar radiation scenarios}

The maximum and minimum temperatures were generated by the process proposed by Matalas (1967). First, the historical maximum and minimum temperatures and solar radiation data series were reduced to residual elements. In this stage, monthly means and standard deviations of the maximum and minimum temperatures and solar radiation from 40 years of observed data were calculated for dry and wet days, respectively, at each station. Then the calculated monthly means and standard deviations were smoothed using a Fourier series (Richardson, 1981). The seasonal means and standard deviations 
(a)

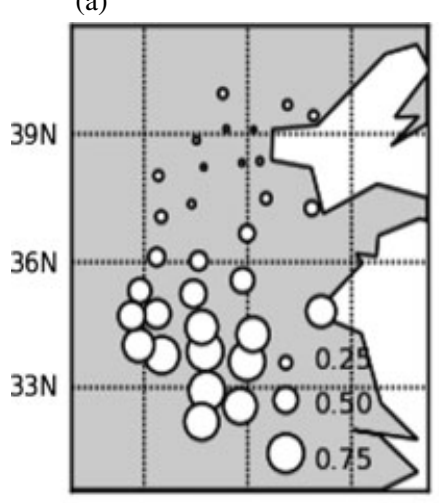

(e)

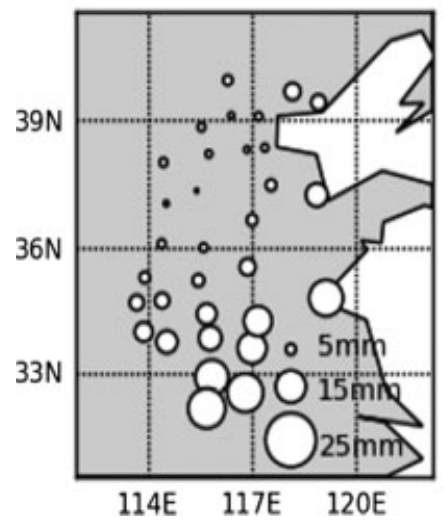

(b)

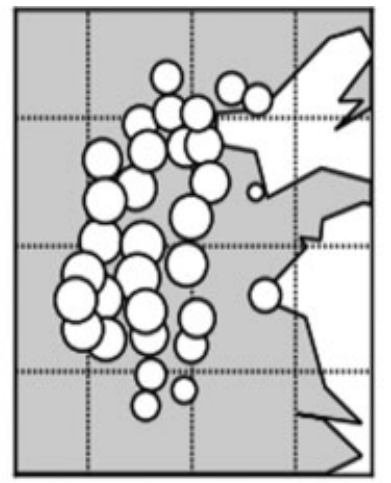

(f)

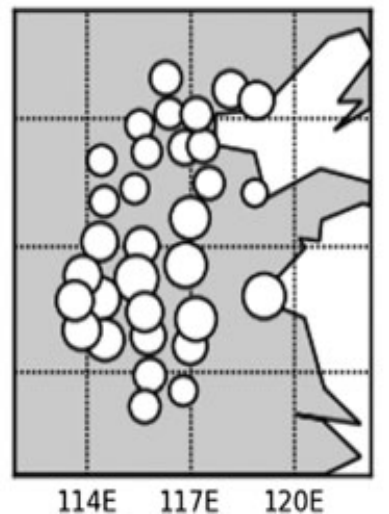

(c)

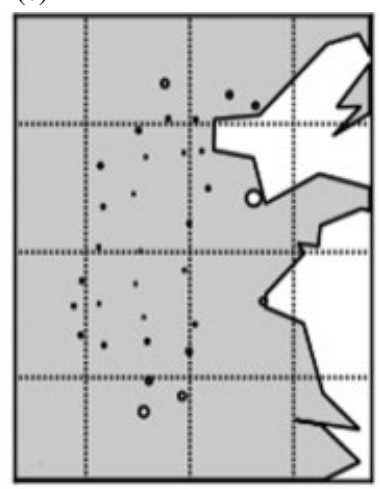

(g)

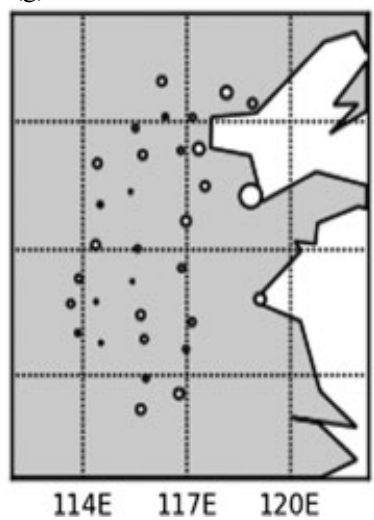

(d)

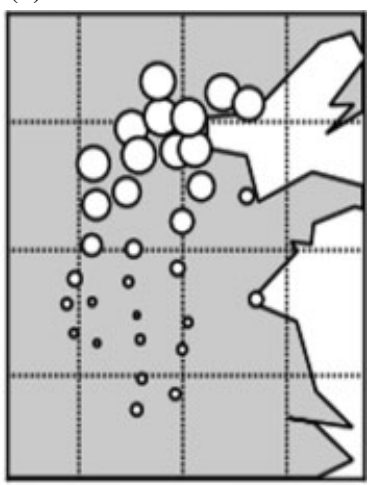

(h)

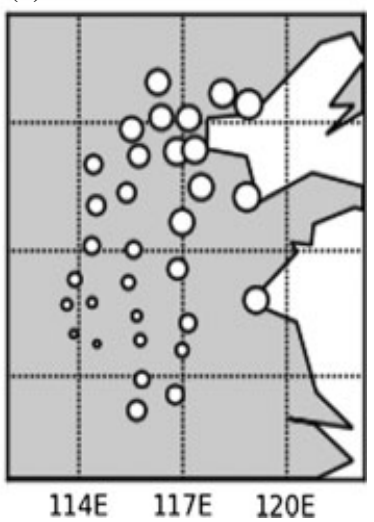

Figure 7. Probability of rain $(\mathrm{a}-\mathrm{d})$ and mean daily intensity $(\mathrm{e}-\mathrm{h})$ during the maize season for states $1-4$, shown in the corresponding columns.

of each of the three elements were removed from the observed daily values to obtain a time series of residual elements (Equations (4) and (5)). Secondly, the obtained residual elements are analyzed to determine the time dependence within each variable and the interdependence between each pair of variables (Equation (6)). Finally, the values of maximum and minimum temperatures and solar radiation were generated by adding the monthly mean to the newly generated residuals multiplied by the standard deviation based on the generated precipitation status of the day (i.e. wet or dry). In our study, ten stochastic generations of daily maximum and minimum temperature for the wheat and maize seasons were generated for each station, conditioned on the simulated precipitation status of each day of the baseline NHMM simulations.

To create the single temperature scenario for the $21 \mathrm{st}$ century, changes in monthly mean maximum and minimum temperatures projected from the 15 -member multimodel ensemble mean were calculated for both wet and dry days (i.e. one mean value for one month), again spatially averaged over the region. The projected changes in monthly maximum and minimum temperature were added to the smoothed daily mean of the corresponding month, which was used to generate ten stochastic sequences of daily maximum and minimum temperature, conditioned on the simulated precipitation status of the day at each station, combined with residuals generated above.
Similarly, to simulate solar radiation in the $21 \mathrm{st}$ century, the smoothed daily mean solar radiation was multiplied by increments in percent. Then it was combined with residuals generated above to generate ten stochastic sequences of daily solar radiation, conditioned on the simulated precipitation status of the day in the $21 \mathrm{st}$ century at each station.

\subsection{Climate scenario}

Combining precipitation, temperature and solar radiation as generated above, 10 climate scenarios were constructed for the wheat and maize seasons at each station: a baseline scenario representing current climate conditions and all nine possible combinations of precipitation $\left(P_{w}, P_{m}, P_{d}\right)$ and solar radiation $\left(S_{-20}, S_{0}, S_{20}\right)$. Accordingly, the scenarios (other than the baseline) are designated with two indices, e.g. $P_{w} S_{20}$ for the 'wet' scenario and a $20 \%$ increase in solar radiation. We believe that all of these scenarios have reasonable probabilities of occurrence.

\subsection{Model performance evaluation}

Three commonly used statistics were used to evaluate simulation results: (1) root mean square error (RMSE) between simulated and observed values, Equation (8); (2) mean absolute error (MAE), the difference between the means of simulation and measurement, Equation (9); (3) mean bias error (MBE), is the difference between 

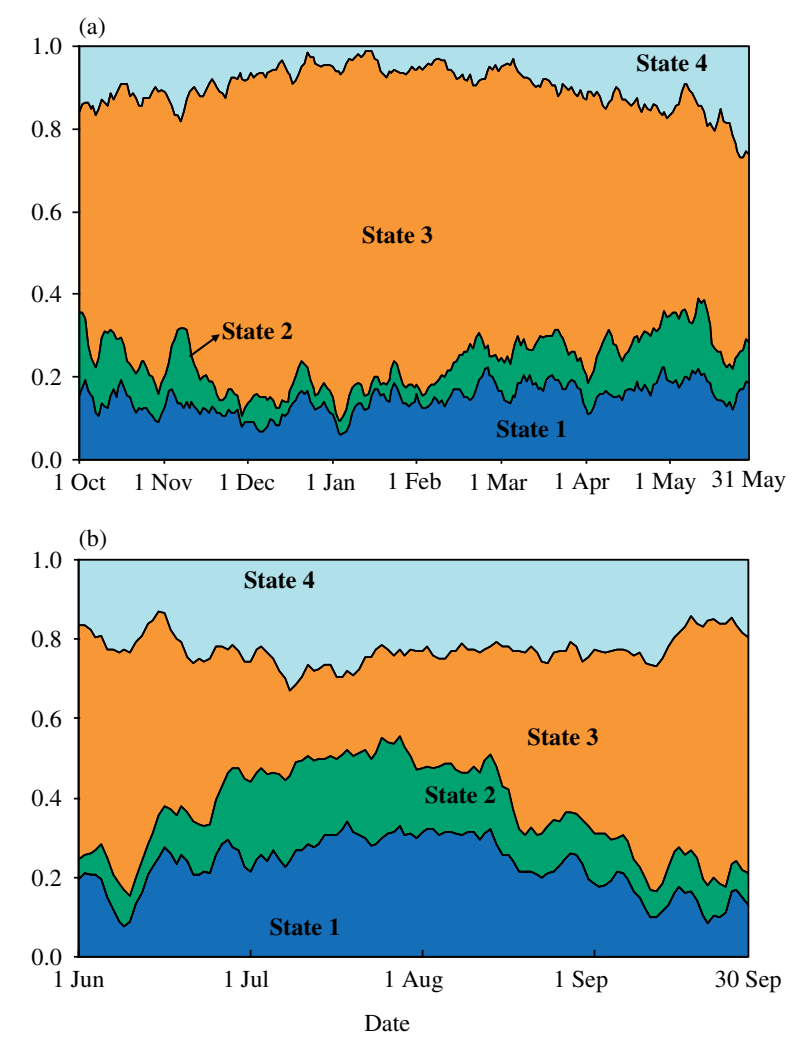

Figure 8. Seasonal climatology of the Viterbi sequence during the wheat season (a) and maize season (b). This figure is available in colour online at wileyonlinelibrary.com/journal/joc

the means of simulation and measurement, Equation (10) and (4) model efficiency (ME) between measured and simulated values, Equation (11).

$$
\begin{gathered}
\mathrm{RMSE}=\sqrt{\frac{1}{n} \sum_{i=1}^{n}\left(P_{i}-O_{i}\right)^{2}} \\
\mathrm{MAE}=\frac{1}{n} \sum_{i=1}^{n}\left|P_{i}-O_{i}\right| \\
\mathrm{MBE}=\frac{1}{n} \sum_{i=1}^{n}\left(P_{i}-O_{i}\right) \\
\mathrm{ME}=1.0-\frac{\sum_{i=1}^{n}\left(P_{i}-O_{i}\right)^{2}}{\sum_{i=1}^{n}\left(O_{i}-O_{\mathrm{avg}}\right)^{2}}
\end{gathered}
$$

where $P_{i}$ is the $i$ th simulated value, $O_{i}$ is the $i$ th observed value, $O_{\text {ave }}$ is the average of the observed values, respectively, and $\mathrm{n}$ is the number of data pairs. RMSE represents overall error weighted by the square of deviations. MAE also represents overall error, but it is considered a more robust measure of accuracy since it is less sensitive to large predicted departures from the mean (Moron and Ullmann, 2005). MBE indicates the average over- or under-estimation. ME is equivalent to the coefficient of determination $\left(R^{2}\right)$, if the values fall around a 1:1 line of simulated versus observed data, but ME is generally lower than $R^{2}$ when the predictions are biased, and can be negative (Legates and McCabe, 1999).

\section{Results}

\subsection{Baseline}

\subsubsection{Rainfall simulations}

5.1.1.1. Seasonal cycle: Figure 9 shows the climatological seasonal cycle of station-averaged observed rainfall and the initial simulation during the wheat and maize growing seasons. The simulated rainfall was low during the wheat growing season (Figure 9(a)), which in consistent with dominant distribution of the dry state (State 3, Figure 8(a)). For the maize season, the simulated rainfall was relatively low in the early and late part of the season and high in the middle season. This is also in accordance with states distribution in the maize season, where the dry state is dominant in the early and late parts of the season and the four states occupy almost equal probability space in the middle of the season (Figure 8(b)). Compared with the seasonal cycle of observed rainfall, the simulation showed some biases in both amplitude and shape. For the wheat season (Figure 9(a)), the observed rainfall was underestimated in the early and late parts of the season, but overestimated from December to March.
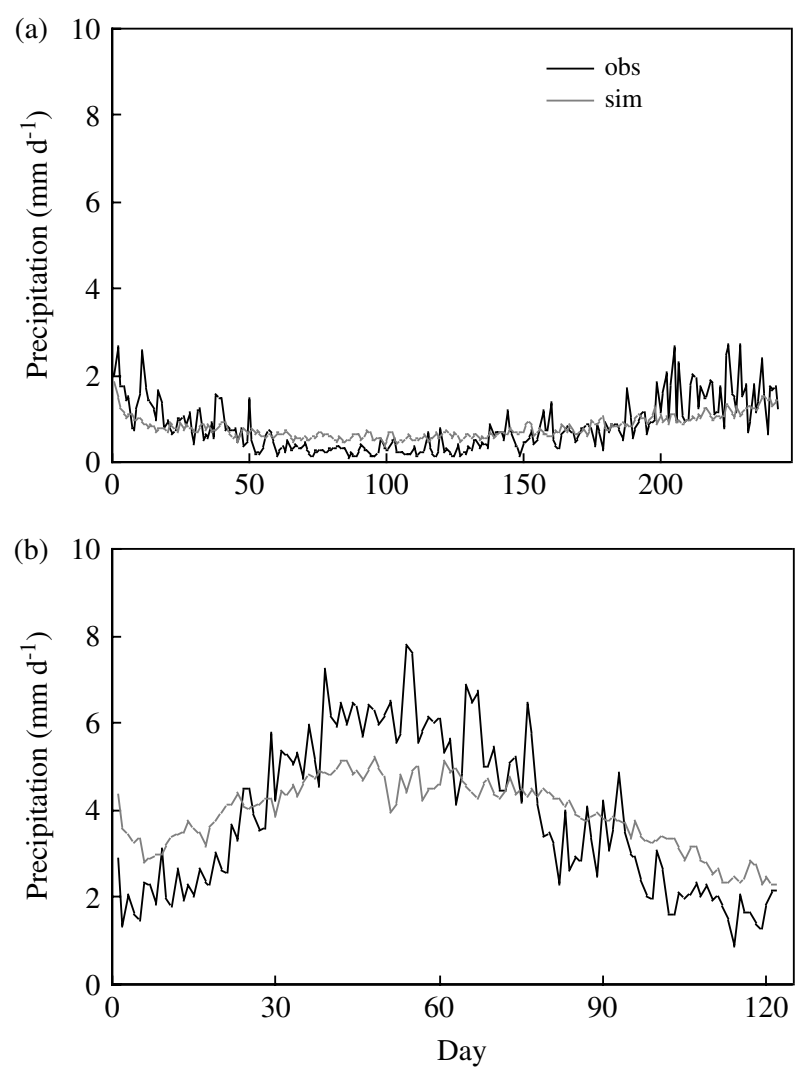

Figure 9. Seasonal cycle of station-averaged precipitation in the observations (obs) and initial 20th-century simulations (sim) for the wheat season (a) and maize season (b). 
For the maize growing season (Figure 9(b)), the simulations overestimated the observed rainfall in June and from the middle of August to September, but underestimated the observations during the middle part of the season. Similar bias patterns were found in Greene et al. (2011), who attributed them to model constraints (e.g. the need to maintain the Markov property, the conditional independence assumption).

Such a mismatch between simulated and observed rainfall could result in significant differences in simulations of crop production and water-use. Therefore, it was necessary to undertake a bias correction to make the seasonal cycle of the simulated rainfall better match the observed. To accomplish this, a method similar to that proposed by Greene et al. (2011) was employed. First, a correction factor was obtained for each day in the climatological seasonal cycle to compensate the overestimation or underestimation of rainfall during the wheat and maize seasons (Figure 10(a) and (b)). To do this, the ratio of the differences between the observed and simulated rainfall to the latter were calculated. Then, a second-order polynomial was fit to the obtained ratio values for both wheat and maize seasons (Figure 10(a) and (b)). The fitted values (FV) were then used to re-scale the simulated rainfall within each simulated crop season, by multiplying the daily simulated rainfall by $(1+\mathrm{FV})$. The climatologies of the bias-corrected baseline rainfall simulations are shown in Figure 10(c) for the wheat season and Figure 10(d) for the maize season. After correction, RMSE, MAE and MBE of daily rainfall during the two crop seasons altogether decreased to $0.59,0.41$ and $0.002 \mathrm{~mm}$, respectively, compared with $0.78,0.56$ and $0.01 \mathrm{~mm}$ of that without correction (Table II). The ME was also improved
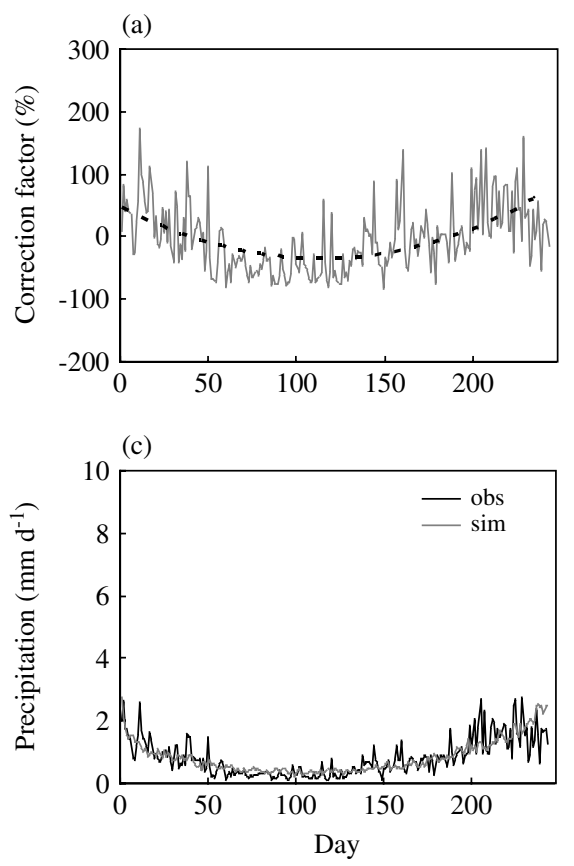

from 0.80 between observations and uncorrected simulations to 0.89 between the observed values and corrected simulations (Table II). The bias-corrected rainfall simulations improve considerably the match to observations. The baseline correction was applied to the 21 st century simulations as well, considering that the rainfall simulations under 21 st century are obtained from the initial fit of the NHMM to the observed rainfall.

5.1.1.2. Spatial pattern: Figure 11 shows spatial patterns of bias-corrected baseline rainfall simulations for the wheat and maize seasons. The rainfall simulations during the wheat season (Figure 11(a)) and maize season (Figure 11(b)) capture well the general N-S rainfall gradients shown in the corresponding observations (Figure 2(a) and (d)). Among 32 stations, the difference of averaged daily rainfall between simulations and observations ranged from -0.1 to $0.1 \mathrm{~mm}$ during the season of wheat, and from -0.2 to $0 \mathrm{~mm}$ during that of maize, demonstrating that the NHMM is successful at the regional scale. The simulated annual average rainy days were from 65 days at Baxian to 120 days at Gushi, which agreed well with the corresponding observed number of rainy days, ranging from 67 days and 119 days at two sites, respectively.

\subsubsection{Temperature and solar radiation simulations}

Figure 12(a) shows the comparisons of the seasonal cycle for the observed and generated maximum and minimum temperature at Beijing. In general, simulated maximum and minimum temperature values under baseline matched very well with the observed values. The RMSEs for the
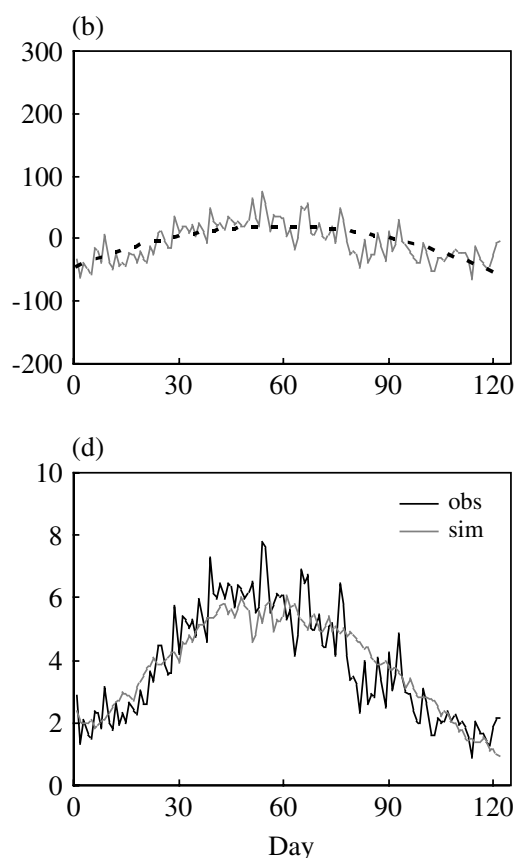

Figure 10. Daily correction factor required to remove seasonal-cycle bias under baseline simulations for the wheat season (a) and maize season (b), and the 2nd-order polynomial fit used to scale the simulations. Seasonal cycle of station-averaged precipitation in the observations and initial baseline simulations corrected for seasonal-cycle shape bias for the wheat season (c) and maize season (d). 
Table II. Root mean square error (RMSE), mean bias error (MBE) and model efficiency (ME) of seasonal cycle of rainfall simulated by the NHMM and temperature and solar radiation generated by the generating process, for the 1966-2005 baseline period.

\begin{tabular}{|c|c|c|c|c|}
\hline \multirow[b]{2}{*}{ Item } & \multicolumn{4}{|c|}{ NHMM } \\
\hline & RMSE (mm) & MAE (mm) & $\operatorname{MBE}(\mathrm{mm})$ & $\mathrm{ME}$ \\
\hline Precipitation (observations vs uncorrected simulations) & 0.78 & 0.56 & 0.01 & 0.80 \\
\hline \multirow[t]{3}{*}{ Precipitation (observations vs corrected simulations) } & 0.59 & 0.41 & 0.002 & 0.89 \\
\hline & \multicolumn{4}{|c|}{ The generating process } \\
\hline & $\operatorname{RMSE}\left({ }^{\circ} \mathrm{C}\right)$ & MAE $\left({ }^{\circ} \mathrm{C}\right)$ & $\operatorname{MBE}\left({ }^{\circ} \mathrm{C}\right)$ & ME \\
\hline Maximum temperature & 0.44 & 0.34 & 0.23 & 0.99 \\
\hline \multirow[t]{2}{*}{ Minimum temperature } & 0.25 & 0.20 & -0.04 & 0.99 \\
\hline & $\operatorname{RMSE}\left(\mathrm{MJ} \mathrm{m}^{-2} \mathrm{~d}^{-1}\right)$ & $\operatorname{MAE}\left(\mathrm{MJ} \mathrm{m}^{-2} \mathrm{~d}^{-1}\right)$ & $\operatorname{MBE}\left(\mathrm{MJ} \mathrm{m}^{-2} \mathrm{~d}^{-1}\right)$ & ME \\
\hline Solar radiation & 0.83 & 0.65 & 0.55 & 0.97 \\
\hline
\end{tabular}

(a)

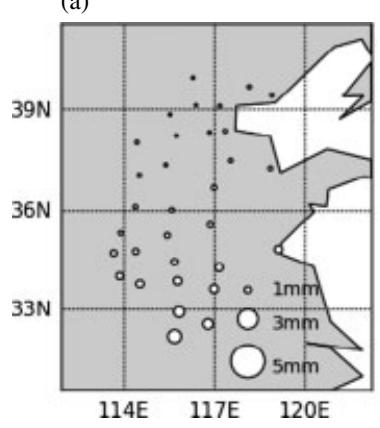

(b)

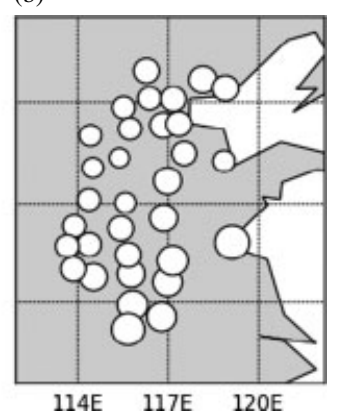

Figure 11. The mean simulated baseline rainfall field for the wheat season (a) and maize season (b).

simulated daily maximum and minimum temperatures were $0.44^{\circ} \mathrm{C}$ and $0.25^{\circ} \mathrm{C}$, respectively, with $\mathrm{ME}$ as high as 0.99 for both variables (Table II). Solar radiation was also well simulated at this site (Figure 12(b)), with RMSE of $0.88 \mathrm{MJ} \mathrm{m}^{-2} \mathrm{~d}^{-1}$, MAE of $0.65 \mathrm{MJ} \mathrm{m}^{-2} \mathrm{~d}^{-1}$ and MBE of 0.55 , respectively (Table II).

\subsection{Twenty-first century}

\subsubsection{Sensitivity analysis of the NHMM model}

Before simulating rainfall for the 21 st century, a sensitivity analysis was conducted to measure the response of the simulated rainfall to the change in input (the change in the scaled daily precipitation, referred to as delta) to the NHMM model. Figure 13 shows a close linear relationship between the delta and the simulated rainfall changes. The changes in simulated rainfall are about half of the values of delta. In this work the amplitude of the change in precipitation over the region is taken to be well simulated by GCMs. To match the change in down-scaled rainfall for the 21 st century and the projected change from GCMs, a correction factor, the inverse of the linear regression coefficient, was thus used to scale the input to the NHMM.

\subsubsection{Rainfall simulations}

The changes in down-scaled mean daily rainfall of 21st century during the wheat and maize seasons are shown
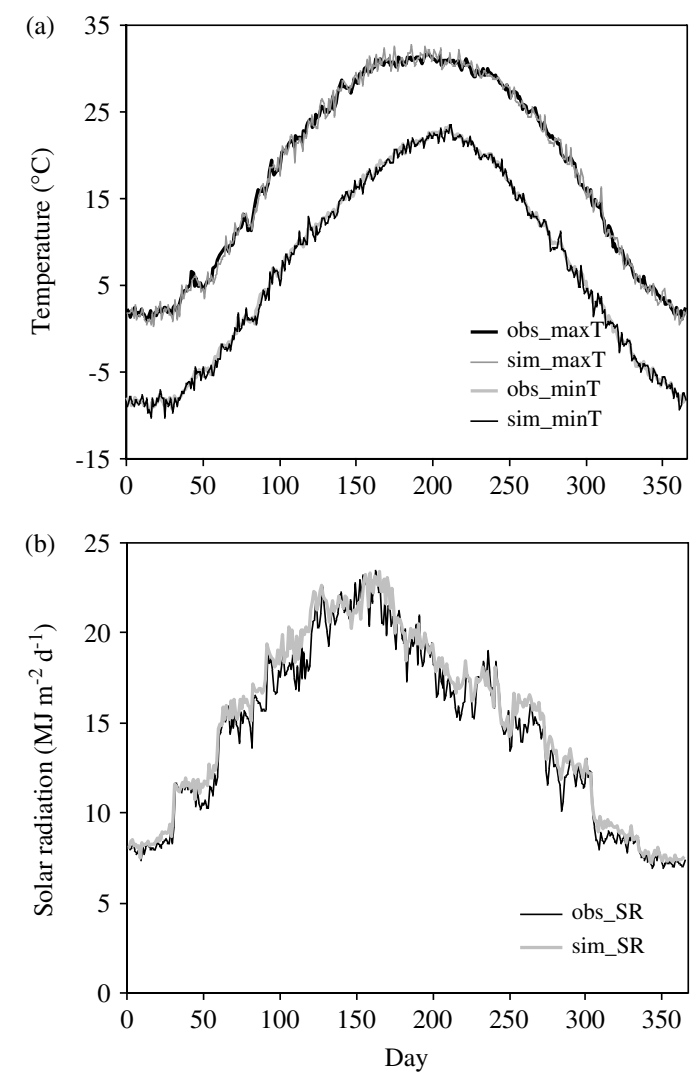

Figure 12. Seasonal cycle of maximum temperature $(\operatorname{maxT})$ and minimum temperature (minT) (a) and solar radiation (SR) (b) in the observations (obs) and baseline simulations (sim) at Beijing.

in Figure 14(a)-(f). The simulated mean daily rainfall of 21 st century under both precipitation scenarios $\mathrm{W}$ and $\mathrm{M}$ (as defined in Section 4.4.) increases everywhere during both seasons (Figure 14(a), (b), (d) and (e)), while it decreases at all stations during the two seasons under scenario D (Figure 14(c) and (f)). This also can be diagnosed in terms of shifts in the relative frequencies of the four NHMM states (Table III). From Table III, we can see that, in precipitation scenarios $\mathrm{W}$ and $\mathrm{M}$, states 1,2 and 4 became more frequent, especially state 4 , while the dry state became less frequent, for both wheat 


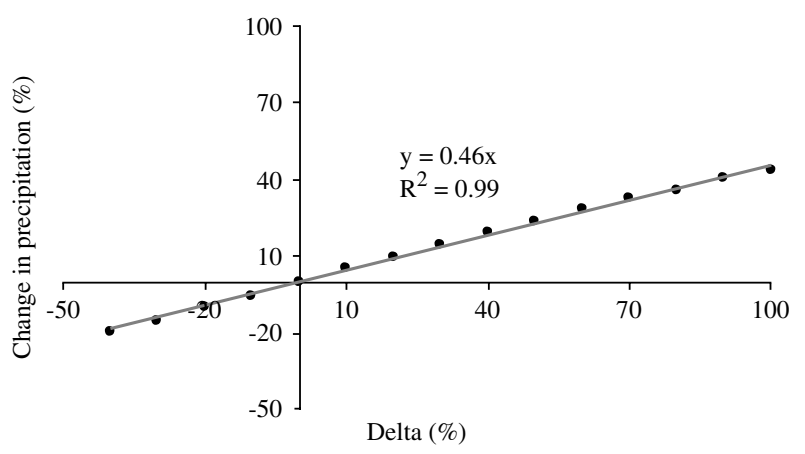

Figure 13. The relationship between the change (delta) in the precipitation used as input to the NHMM and that simulated.

and maize seasons. Under scenario $\mathrm{D}$, the frequencies of the states changed in the opposite sense. The net effect is that down-scaled mean daily rainfall increased under scenarios $\mathrm{W}$ and $\mathrm{M}$ and decreased under scenario D. For the wheat season, the down-scaled mean daily rainfall increased by $23.2-69.7 \%$ (mean, 43.4\%) among stations under scenario W (Figure 14(a)) and 13.9-28.3\% (mean, 18.9\%) under scenario M (Figure 14(b)). Under both scenarios, the largest fractional rainfall increase occurred in the northern part of the NCP. This might be attributed to the dependence of equilibrium state probabilities on the change in the input to the NHMM (Figure 15). Figure 15(a), which describes the wheat season, shows that as the input increases, the relative frequency of state 4 (wet in the north) increases the most rapidly, compared with the increase of those of state 1 (wet in the south) and state 2 (wettest), which decrease when the input is larger than 3 and $4 \mathrm{~mm} \mathrm{~d}^{-1}$, respectively. The relative frequency of state 3 , the dry state, decreases rapidly as the input increases, indicating that more days with dry state will become wet days in the northern part of the NCP. Under scenarios W and M, the precipitation is projected to increase, which results in the largest precipitation increase in the northern NCP. Under scenario $\mathrm{D}$, the decrease of the simulated rainfall ranged from -6.5 to $-0.1 \%$ (mean, $-2.1 \%$ ). Due to this small change in projected precipitation, no clear change in the spatial pattern of simulated mean daily rainfall was apparent. For the maize season (Figure 15(b)), the simulated rainfall increased from $1.7 \%$ to $29.9 \%$ (mean, $23.2 \%$ ) under scenario $\mathrm{W}$ and $0.4 \%$ to $10.1 \%$ (mean, $6.1 \%$ ) under scenario $M$ (Figure 14(d) and (e)) and decreased from -24.6 to $-2.4 \%$ (mean, $-18.9 \%$ ) under scenario D (Figure 14(f)). The changes in down-scaled mean daily rainfall are roughly similar for all stations under three scenarios due to the parallel change in states 1, 2 and 4.

Figure 16 shows contour maps of the multimodel mean precipitation change projected directly from the GCMs for the wheat and maize seasons. Compared to the changes in down-scaled rainfall during the corresponding crop season under scenario M (Figure 14(b) and (e)), we can see that they show similar spatial patterns



(d)

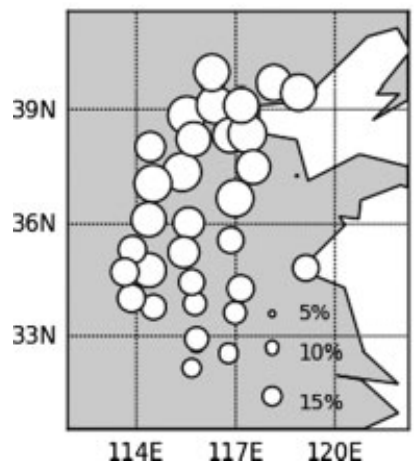

(b)

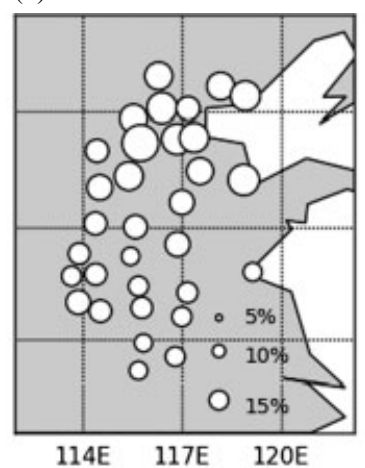

(e)

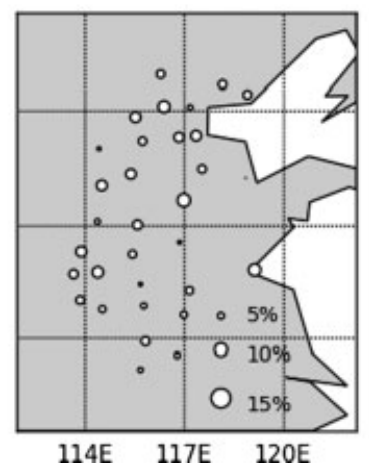

(c)

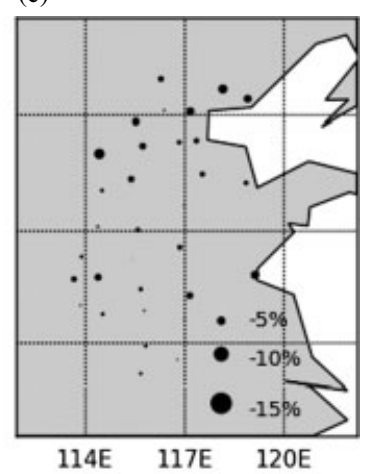

(f)

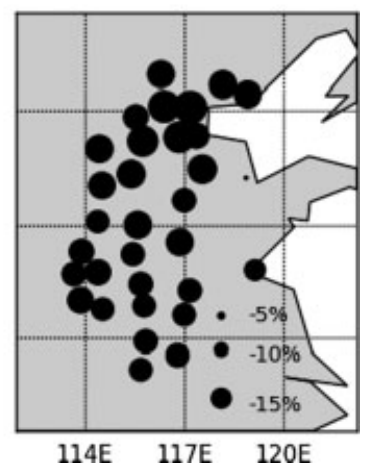

Figure 14. Percentage changes of the corrected simulated mean precipitation for the 21 st century, using the largest projected precipitation increase by an individual GCM (a, d), multi-model mean (b, e) and the largest projected precipitation decrease by an individual GCM (c, f). The upper and lower panels represent the wheat season and maize season, respectively. 
Table III. Changes in relative state occupation frequencies during the wheat and maize seasons for the three scenarios, in going from the 20th to the 21 st century.

\begin{tabular}{|c|c|c|c|c|c|c|c|c|}
\hline \multirow[b]{2}{*}{ Scenarios } & \multicolumn{4}{|c|}{ Wheat season $(\%)$} & \multicolumn{4}{|c|}{ Maize season $(\%)$} \\
\hline & $\begin{array}{c}\text { State } \\
1\end{array}$ & $\begin{array}{c}\text { State } \\
2\end{array}$ & $\begin{array}{c}\text { State } \\
3\end{array}$ & $\begin{array}{c}\text { State } \\
4\end{array}$ & $\begin{array}{c}\text { State } \\
1\end{array}$ & $\begin{array}{c}\text { State } \\
2\end{array}$ & $\begin{array}{c}\text { State } \\
3\end{array}$ & $\begin{array}{c}\text { State } \\
4\end{array}$ \\
\hline $\mathrm{W}$ & 1.3 & 2.9 & -15.1 & 10.9 & 4.0 & 3.8 & -17.1 & 9.3 \\
\hline M & 1.2 & 1.5 & -5.9 & 3.2 & 1.1 & 0.9 & -3.9 & 1.9 \\
\hline $\mathrm{D}$ & 0.1 & 0.0 & -0.1 & 0.0 & -3.7 & -3.0 & 12.3 & -5.6 \\
\hline
\end{tabular}
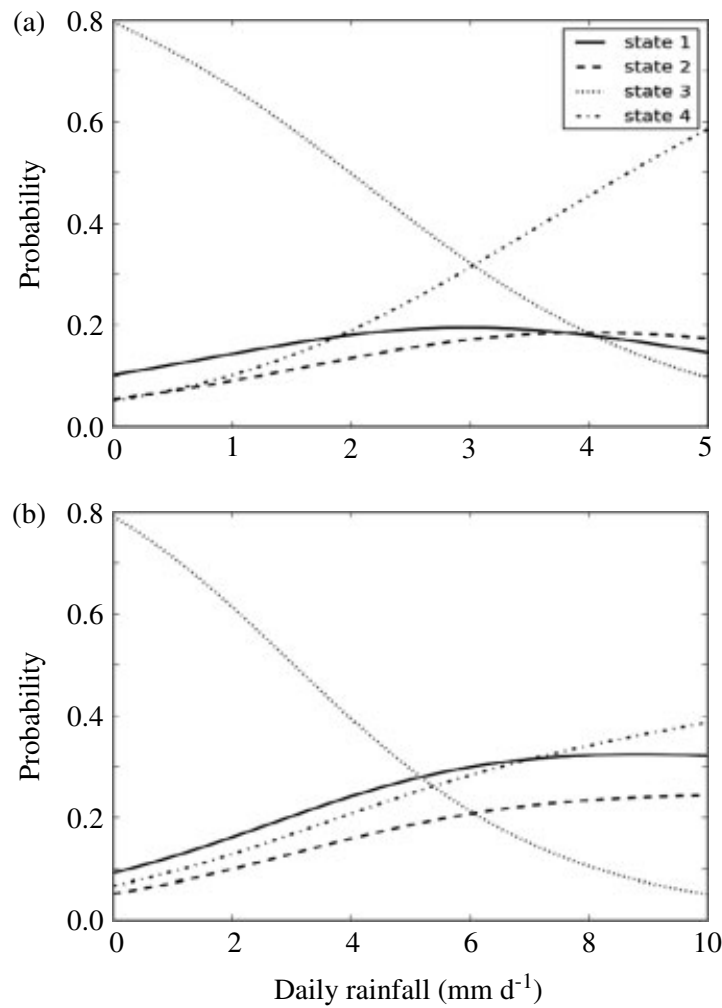

Figure 15. Dependence of equilibrium state probabilities on rainfall input to the NHMM during the wheat season (a) and maize season (b).

of precipitation for each crop season, although there were some differences at finer scales. For example, for wheat season, the magnitudes of rainfall increases at the western sites were larger than those at the eastern sites between $38^{\circ} \mathrm{N}$ and $40^{\circ} \mathrm{N}$. This occurs because precipitation at the western sites is lower to begin with, i.e. the probability of dry state, which is more sensitive to precipitation increase, is higher. The NHMM simulations can capture this detail, while the multimodel mean fails to discern it.

The simulated rainfall changes can also been seen from the daily rainfall distributions (Figure 17), which shows daily rainfall distributions under the baseline and scenario $\mathrm{W}$ in the 21 st century, pooled across stations. Compared with baseline, daily rainfall frequencies under scenario $\mathrm{W}$ in 21st century are larger for almost all bins except the lowest (which include dry days) during both wheat season (Figure 17(a)) and maize season (Figure 17(b)). (a)

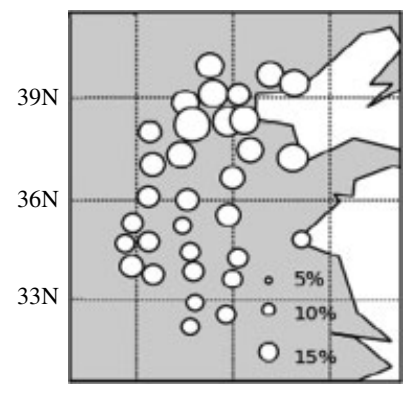

(c)

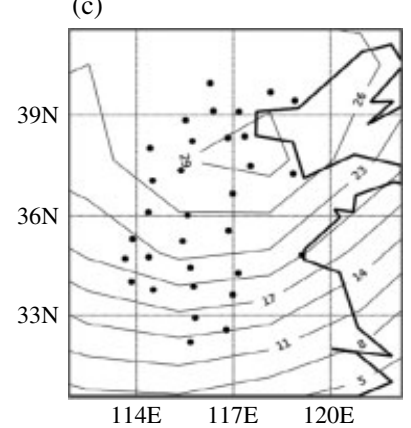

(b)

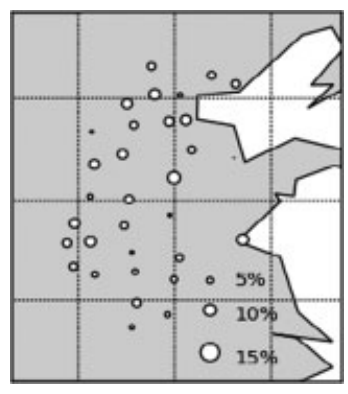

(d)

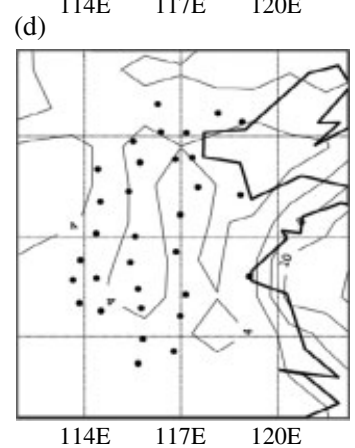

Figure 16. The percent changes of the corrected simulated mean precipitation for the 21 st century using multi-model mean (upper panel) and the precipitation projected from multimodel mean (lower panel) during the wheat season $(a, c)$ and maize season $(b, d)$. The unit of precipitation: $\left(\mathrm{mm} \mathrm{d}^{-1}\right)$.

\subsection{Changes in temperature and solar radiation}

For the wheat season, both regionally-averaged maximum and minimum temperatures increase by $3.7^{\circ} \mathrm{C}$ using the GCM multi-model mean (Figure 5). For the maize season, regionally-averaged maximum and minimum temperatures both increase by $3.6^{\circ} \mathrm{C}$. There are only small differences in the changes in simulated mean daily temperature among stations (for example, the changes are 3.67, 3.60, 3.69 and $3.63^{\circ} \mathrm{C}$ at Beiing, Kaifeng, Shouxian and Xihua, respectively). The differences in simulated daily solar radiation among stations are also not obvious. This indicates that the changes in the number of wet \& dry days in the 21 st century only have a minor impact on the simulated temperature and solar radiation.

\section{Summary and conclusions}

The critical climate variables associated with agricultural production include precipitation, temperature and solar radiation. In this study, we constructed climate scenarios of these three weather elements during the wheat and maize seasons for the NCP, the largest agricultural area in China. The principal difference with respect to the conventional approach is that climate scenarios were developed by combining the scenarios of precipitation, temperature and solar radiation generated in terms of stochastic daily weather sequences, considering the characteristics of their projected changes. 

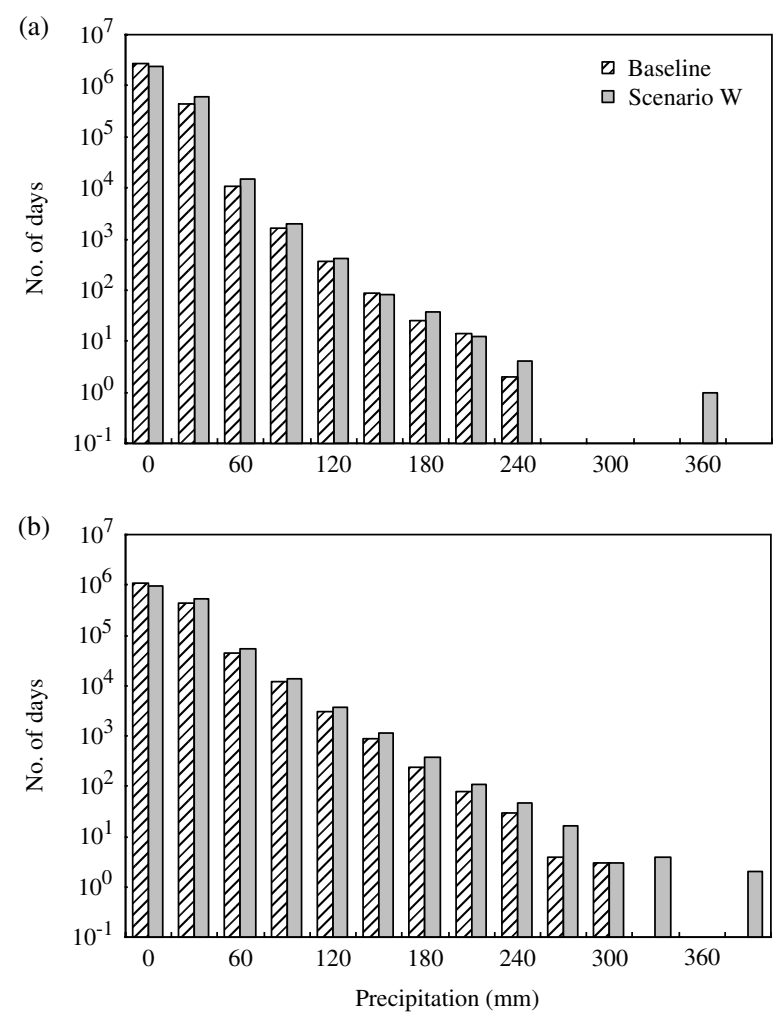

Figure 17. Changes in precipitation during the wheat season (a) and maize season (b), polled over stations. Baseline referred to 20th century; Scenario W referred to 21 st century precipitation scenario driven by the largest projected increase by an individual GCM. The unit of precipitation: $\left(\mathrm{mm} \mathrm{d}^{-1}\right)$.

A NHMM was used to down-scale daily precipitation projections to 32 stations during winter wheat and summer maize seasons in the NCP for a baseline period of 1966-2005 and the late 21st century under the IPCC A1B scenario for 2080-2099, using selected GCMs. A climatological seasonal cycle of regionally-averaged reanalysis precipitation, served as input to the NHMM for the baseline simulation; this input was scaled by the precipitation changes from GCM projections to construct down-scaled stochastic simulations of daily precipitation in the $21 \mathrm{st}$ century. Considering the large uncertainty in precipitation change projected by different GCMs, three different precipitation scenarios were constructed, driven by: the GCM with the largest projected precipitation increase, the GCM multi-model mean, and the GCM with the largest projected precipitation decrease. Daily maximum and minimum temperatures and solar radiation were simulated as described in Matalas (1967), conditioned on wet/dry status as determined from the simulated rainfall. Three hypotheses for the changes in solar radiation were made, considering the large uncertainty about its changes in the future. The generated rainfall, temperature and solar radiation were combined to produce a baseline scenario and 9 climate change scenarios.

The NHMM was shown to be able to adequately reproduce spatial patterns of the observed rainfall by using the interpolated regionally averaged reanalysis precipitation as driver. Shape bias in the simulated seasonal cycle of precipitation was corrected using a method similar to that used in Greene et al. (2011). The correction factor was applied to all stations and for both the 20th and 21st centuries, since all stations had similar climatological characteristics and the shape of climatological annual cycle of the NHMM input for 21st century was based on that of the input for the 20th century.

GCMs models are the most highly developed tools currently available to model climate and its changes. However, GCMs only support large-scale climate information due to their limited resolution, and exhibit large uncertainties in their projections of precipitation. The NHMM is a tool for producing down-scaled stochastic daily rainfall sequences having realistic daily distributions over a network of stations. Such sequences, with their fine temporal and spatial resolution, can meet the needs of agricultural system models. Moreover, the down-scaled daily rainfall over a network of precise locations is very useful for water resources management, since small changes in precipitation can directly affect irrigation strategies in relatively dry climates or seasons, such as the wheat season in the NCP.

In going to the 21st century, rainfall will increase for both wheat and maize seasons at all 32 stations in precipitation scenario $\mathrm{W}$ and scenario $\mathrm{M}$, with magnitude increasing from south to north for both crop seasons. From a probabilistic perspective, a drying of the NCP is less likely. Temperature would increase in both wheat and maize growing seasons in going to the 21 st century, with a reasonably strong model consensus regarding for the study area. Chen et al. (2012) used a crop simulation model to examine the relative contributions of the variability and trends in temperature, solar radiation and precipitation during 1961-2003 to wheat and maize yields in the NCP, and found that the decreasing trend in solar radiation showed the strongest isolated impact on simulated yields. However, there are large uncertainties concerning the effects of human activity on solar radiation in the future, and thus, three hypotheses were put forward, spanning a range of possible future changes.

Crop production is affected biophysically by weather variables, including rising temperatures, changing precipitation and radiation (Parry et al., 2004). Without irrigation, rainfall is extremely important to agricultural production in the NCP (Chen et al., 2012) due to the fact that precipitation is scarce. The projected increase in precipitation will provide favourable moisture conditions for the production of crops in the NCP, including wheat and maize, especially in the northern part. However, the increase in temperature, together with increased solar radiation, would increase the demand for water, which was worsen the water resources condition having been faced in the study region. The increased temperature would also accelerate the growth of crop and shorten the growth period, resulting in a decrease in yield. However, the changes in regional crop yield are a result of the effects of climate change and the availability and effectiveness of adaptations, which should be studied further. 
To investigate the potential impact of climate change on crop production, weather variables, including maximum and minimum air temperature, solar radiation and total rainfall, are one of the key inputs required for the operation of crop models (Hoogenboom, 2000). In this study we have attempted to create climate scenarios of temperature, precipitation and solar radiation in the form of stochastic daily weather sequences. These scenarios can be used with crop simulation models to assess climate change impacts on agricultural production and water resources. Our approach should be very useful for evaluating the potential effects of changes in temperature, precipitation and solar radiation, to agricultural system, as well as their comprehensive impacts. We believe that this methodology for developing scenarios of precipitation, temperature and solar radiation can be used in other regions as well. However, there is some uncertainty regarding the method used in this study. Precipitation occurrence and amount were generated independently, and the other variables were then generated based on the stochastically generated precipitation occurrence. A possible limitation of this method is that only that part of the dependency that is related to precipitation was captured for simulating temperature and solar radiation conditioned on precipitation. One additional source of uncertainty is that a stationary assumption, i.e., that variability in the future, apart from the change in seasonal cycle that was simulated, is assumed to be similar to variability in the past. There are also some caveats about the results. For example, the 'realism' of the down-scaling results is contingent on that of the GCM projections, although GCMs may be able to simulate reasonably well many large scale features of climate. There is also a stationary assumption, of the NHMM station rainfall distributions for each state, i.e., the NHMM assumes that the frequency of states may change but not the states themselves (Greene et al., 2011). Furthermore, potential changes in inter-annual variability are not simulated here. However they can in principle be included in the NHMM framework, if the 'delta' is allowed to vary from year to year (Siegfried et al., 2011). Although the seasonal cycle of the predictors-reanalysis precipitation and GCM outputs did not play the critical role in the precipitation simulations of the NHMM, a subsequent down-scaling study that takes into account daily values of both the reanalysis data and GCM output would be of interest. The latter should be readily available in the CMIP5 ensemble.

\section{Acknowledgements}

We wish to thank the colleagues from the International Research Institute for Climate and Society (IRI), Columbia University for assistance with the data processing and helpful comments. The NHMM software (MVNHMM) was developed by S. Kirshner and can be obtained online at http://www.stat.purdue.edu/ $\sim$ skirshne/MVNHMM/. The NCEP-NCAR reanalysis data were provided by the National Oceanic and
Atmospheric Administration (NOAA)-CIRES Climate Diagnostics Center, Boulder, Colorado, from their Web site (online at http://www.cdc.noaa.gov). The observed climate data were kindly provided by the China Meteorological Administration. This work was supported by grants from National Oceanic and Atmospheric Administration (NOAA), NA050AR4311004, and the Earth Institute at Columbia University. AWR and AMG were partly supported by U.S. Department of Energy grant DE-SC0006616.

\section{References}

AbouRizk SM, Wales RJ. 1997. Combined discrete-event/continuous simulation for project planning. Journal of Construction Engineering and Management 123: 11-20.

Bates BC, Charles SP, Hughes JP. 1998. Stochastic down-scaling of numerical climate model simulations. Environmental Modelling \& Software 13: 325-331.

Chen C, Baethgen W, Robertson A. 2012. Contributions of individual variation in temperature, solar radiation and precipitation to crop yield in the North China Plain, 1961-2003. Climatic Change. DOI: 10.1007/s10584-012-0509-2

Dai A. 2006. Precipitation characteristics in eighteen coupled climate models. Journal of Climate 19: 4605-4630.

Dempster AP, Laird NM, Rubin DB. 1977. Maximum likelihood from incomplete data via EM algorithm. Journal of the Royal Statistical Society: Series B (Methodological) 39(1): 1-38.

Evans TE. 1996. The effects of changes in the world hydrological cycle on availability of water resources. In Global Climate Change and Agricultural Production, Bazzaz F, Sombroek W (eds). Wiley: Chichester; 248.

Fan L, Fu C, Chen D. 2005. A survey on statistical down-scaling in climate studies. Advance in Earth Sciences 20(3): 320-329 (in Chinese).

Giorgi F, Mearns LO. 1991. Approaches to the Simulation of Regional Climate Change: A Review. Reviews of Geophysics 29: 191-216.

Greene AM, Robertson AW, Smyth P, Triglia S. 2011. Down-scaling projections of Indian monsoon rainfall using a nonhomogeneous hidden Markov model. The Quarterly Journal of the Royal Meteorological Society 137: 347-359. DOI: 10.1002/qj.000

Hewitson BC, Grane RC. 1996. Climate down-scaling: Techniques and application. Climate Research 7(2): 85-95.

Hoogenboom G. 2000. Contribution of agrometeorology to the simulation of crop production and its applications. Agricultural and Forest Meteorology 103: 137-157.

Hughes JP, Guttorp P. 1994. A class of stochastic models for relating synoptic atmospheric patterns to regional hydrologic phenomena. Water Resources Research 30: 1535-1546.

Hughes JP, Guttorp P, Charles SP. 1999. A non-homogeneous hidden Markov model for precipitation occurrence. Applied Statistics 48(1): 15-30.

Hulme M, Wigley T, Jiang T, Zhao Z, Wang F, Ding Y, Leemans R, Markham A. 1992. Climate Change due to the Greenhouse Effect and its Implications for China. World Wide Fund for Nature. Gland: Switzerland.

Kalnay E, Kanamitsu M, Kistler R, Collins W, Deaven D, Gandin L, Iredell M, Saha S, White G, Woollen J, Zhu Y, Leetmaa A, Reynolds R, Chelliah M, Ebisuzaki W, Higgins W, Janowiak J, Mo KC, Ropelewski C, Wang J, Jenne R, Joseph D. 1996. The NCEP/NCAR 40-year reanalysis project. Bulletin of the American Meteorological Society 77: 437-472.

Legates DR, McCabe JR. 1999. Evaluating the use of "goodness-of-fit" measures in hydrologic and hydroclimatic model validation. Water Resources Research 35(1): 233-241.

Liu ZF, Xu ZX, Charles SP, Fu GB, Liu L. 2011. Evaluation of two statistical down-scaling models for daily precipitation over an arid basin in China. International Journal of Climatology 31(13): 2006-2020. DOI: 10.1002/joc.2211

Lobell D, Asner G. 2003. Climate and management contributions to recent Trends in U.S. agricultural yields. Science 299: 1032.

Ludwig F, Asseng S. 2006. Climate change impacts on wheat production in a Mediterranean environmental in Western Australian. Agricultural Systems 90: 159-179. 
Matalas NC. 1967. Mathematical assessment of synthetic hydrology. Water Resources Research 3(4): 937-945.

Meehl GA, Covey C, Taylor KE, Delworth T, Stouffer RJ, Latif M, McAvaney B, Mitchell JF. 2007. The WCRP CMIP3 multimodel dataset: A new era in climate change research. Bulletin of the American Meteorological Society 88: 1383-1394.

Mizina SV, Smith JB, Gossen E, Spiecker KF, Witkowski SL. 1999. An evaluation of adaptation options for climate change impacts on agriculture in Kazakhstan. Mitigation and Adaptation Strategies for Global Change 4: 25-41.

Moron V, Ullmann A. 2005. Relationship between sea-level pressure and sea-level height in the Camargue (French Mediterranean Coast). International Journal of Climatology 25: 1531-1540.

Murphy J. 2000. Predictions of climate change over Europe using statistical and dynamical down-scaling techniques. International Journal of Climatology 20: 489-501.

Parry ML, Rosenzweig C, Iglesias A, Livermore M, Fischer G. 2004. Effects of climate change on global food production under SRES emissions and socio-economic scenarios. Global Environmental Change 14: 53-67.

Reilly J, Schimmelpfennig D. 1999. Agricultural impact assessment, vulnerability and the scope for adaptation. Climatic Change $\mathbf{4 3}(4)$ : $745-788$.

Richardson CW. 1981. Stochastic simulation of daily precipitation, temperature, and solar radiation. Water Resources Research 17: $182-190$

Robertson AW, Kirshner S, Smyth PJ. 2003. Hidden Markov models for modeling daily rainfall occurrence over Brazil. Technical Report UCI-ICS 03-27, Information and Computer Science, University of California, Irvine, CA, 36 pp.

Robertson AW, Kershner S, Smyth P. 2004. Down-scaling of daily rainfall occurrence over Northeast Brazil using a hidden Markov model. Journal of Climate 17: 4407-4424.

Siegfried T, Bernauer T, Guiennet R, Sellars S, Robertson A, Mankin J, Bauer-Gottwein P, Yakovlev A. 2011. Will climate change exacerbate water stress in Central Asia? Climatic Change 112: 881-899. DOI: 10.1007/s10584-011-0253-Z
Solomon SD, Qin M, Manning Z, Chen M, Marquis KB, Averyt M, Tignor MHL. 2007. Climate Change 2007: The Physical Science Basis. Contribution of Working Group I to the Fourth Assessment Report of the Intergovernmental Panel on Climate Change. Cambridge University Press: Cambridge; 996.

Spaeth SC, Sinclair TR, Ohnuma T, Konno S. 1987. Temperature, radiation, and duration dependence of high soybean yields: measurement and simulation. Field Crops Research 16: 297-307.

Viner D, Hulme M. 1994. The Climate Impacts LINK Project: Providing Climate Change Scenarios for Impacts Assessment in the UK. DoE/CRU Report: Norwich.

Viterbi AJ. 1967. Error bounds for convolutional codes and an asymptotically optimum decoding algorithm. IEEE Transactions on Information Theory 13(2):260-269.

Wang HX, Zhang L, Dawes WR, Liu CM. 2001. Improving water use efficiency of irrigated crops in the North China Plainmeasurements and modeling. Agricultural Water Management 48: $151-167$.

Wang EL, Yu Q, Wu DR, Xia J. 2008. Climate, agricultural production and hydrological balance in the North China Plain. International Journal of Climatology 28(14): 1959-1970.

Wild M, Gilgen H, Roesch A, Ohmura A, Long CN, Dutton EG, Forgan B, Kallis A, Russak V, Tsvetkov A. 2005. From dimming to brightening: decadal changes in solar radiation at earth's surface. Science 308: 847-850.

Wilks DS, Wilby RL. 1999. The weather generation game: A review of stochastic weather models. Progress in Physical Geography 23: 329-357.

Wu DR, Yu Q, Lu CH, Hengsdijk H. 2006. Quantifying production potentials of winter wheat in the North China Plain. European Journal of Agronomy 24: 226-235.

Wu DR, Yu Q, Wang EL, Hengsdijk H. 2008. Impact of spatial-temporal variations of climatic variables on summer maize yield in the North China Plain. International Journal of Plant Production 2: 1-18.

Yevjevich V. 1972. Structural Analysis of Hydrologic Time Series: Hydrology. Colorado State University: Fort Collins, CO; 56. 